\title{
Adaptive changes in the fungal cell wall mediate copper homeostasis
}

Corinna Probst 1,2,3, Sarela Garcia-Santamarina ${ }^{2,3, \# ~, ~ J a c o b ~ T . ~ B r o o k s ~}{ }^{4}$, Inge Van Der Kloet ${ }^{1,2,3}$, Dennis

Duke University School of Medicine, Departments of Medicine ${ }^{1}$, Molecular Genetics/Microbiology²,

Corresponding Author:

16303 Sands Research Building, Research Drive, DUMC 102359

17 Duke University Medical Center, Durham, NC, USA, 27710

18 andrew.alspaugh@duke.edu

21 Key words: Cryptococcus neoformans, chitin, chitosan, glucan, trace metals, chelation 


\section{$\underline{\text { Abstract }}$}

Copper homeostasis mechanisms are essential for microbial adaption to changing copper levels within the host during infection. In the opportunistic fungal pathogen Cryptococcus neoformans (Cn), the $\mathrm{Cn}$ Cbi1/Bim1 protein is a newly identified copper binding and release protein that is highly induced during copper limitation. Recent studies demonstrated that Cbi1 functions in copper uptake through the Ctr1 copper transporter during copper limitation. However, the mechanism of Cbi1 action is unknown. The fungal cell wall is a dynamic structure primarily composed of carbohydrate polymers, such as chitin and chitosan, polymers known to strongly bind copper ions. We demonstrated that Cbi1 depletion affects cell wall integrity and architecture, connecting copper homeostasis with adaptive changes within the fungal cell wall. The $c b i 1 \Delta$ mutant strain possesses an aberrant cell wall gene transcriptional signature as well as defects in chitin and chitosan deposition. These changes are reflected in altered macrophage activation and changes in the expression of specific virulence-associated phenotypes. Furthermore, using $\mathrm{Cn}$ strains defective in chitosan biosynthesis, we demonstrated that cell wall chitosan modulates the ability of the fungal cell to withstand copper stress. In conclusion, our data suggest a dual role for the fungal cell wall, in particular the inner chitin / chitosan layer, in protection against toxic levels of copper and providing a source of metal ion availability during copper starvation. Given the previously described role for Cbi1 in copper uptake, we propose that this copper-binding protein is involved in shuttling copper from the cell wall to the copper transporter Ctr1 for regulated microbial copper uptake.

\section{Author summary}

Microorganisms must be equipped to readily acquire essential micro-nutrients like copper from nutritionally poor environments while simultaneously shielding themselves from conditions of metal 
pathogen Cryptococcus neoformans $(\mathrm{Cn})$ by defining physiological roles of the newly described copper-

47 binding and release protein Cn Cbi1/Bim1. Highly induced during copper limitation, Cbi1 has been shown to interact with the high-affinity copper transporter Ctr1. We defined Cbi1-regulated changes in the fungal cell wall, including controlling levels of the structural carbohydrates chitin and chitosan. These polysaccharides are embedded deeply in the cell wall and are known to avidly bind copper. We also defined the host immunological alterations in response to these cell wall changes. Our data suggest a model in which the fungal cell wall, especially the chito-oligomer layer, serves as a copper-binding structure to shield the cell from states of excess copper, while also serving as a copper storage site during conditions of extracellular copper depletion. Given its ability to bind and release copper, the Cbi1 protein likely shuttles copper from the cell wall to copper transporters for regulated copper acquisition.

Metal ions serve important and varied roles in the host-pathogen interaction. Transition metals, such as copper and iron, are essential micronutrients for both the host and pathogen, required as cofactors for cellular respiration and other central cell processes [1, 2]. However, non-bound metal ions can

61 be very cytotoxic. The requirement that microbial cells have ready access to non-toxic levels of transition metals governs a host process called "nutritional immunity". In this process, the host starves invading microbial pathogens by sequestering essential metals under certain conditions. Conversely, the host may

64 actively bombard the pathogen with toxic levels of metals in other conditions. Nutritional immunity is best studied within microbe-containing macrophages in which $\mathrm{Mn}$, Fe, and $\mathrm{Zn}$ are typically restricted by the 66 host, while toxic levels of $\mathrm{Cu}$ are actively transported into the phagolysome by the ATP7A copper pump $67[3]$. 
The genes that control copper homeostasis in fungi are under tight transcriptional control in response to extracellular copper concentrations. In contrast to many other fungi, the human fungal pathogen Cryptococcus neoformans $(\mathrm{Cn})$ has a single transcription factor, Cuf1, that regulates the transcriptional response to both copper excess and copper starvation [4]. Within the Cuf1 regulon, one of the most highly induced genes during copper starvation is Cn CBI1/BIM1 (CNAG_02775), encoding a GPIanchored protein that interacts with the $\mathrm{Ctr} 1$ high-affinity $\mathrm{Cu}^{+}$transporter. The $\mathrm{Cn} \mathrm{Cbi1}$ copper binding and release protein, previously named Bim1, is required for growth in low copper conditions and therefore for effective brain colonization by this neuropathogenic yeast [5]. Cbi1 shares limited homology with lytic polysaccharide monooxygenase (LPMO) proteins that cleave glycosidic bonds within complex carbohydrates such as cellulose, starch, and chitin . Also similar to LPMOs and copper chaperones, $\mathrm{Cn}$ Cbi1/Bim1 binds copper in a histidine brace region, and it releases copper in reponse to low levels of hydrogen peroxide. However, the purified $\mathrm{Cn}$ Cbi1/Bim1 protein does not possess the redox activity associated with most sugar-modifying enzymes $[6,7]$. It also lacks recognizable polysaccharide binding sites present in LPMOs $[6,7]$. Its specific function in Ctr1-mediated uptake of copper is therefore unclear. Based upon previous data, it has been proposed that $C n$ Cbi1/Bim1 acts as an intermediary copper binding protein, delivering copper to Ctr1 for cellular copper acquisition. However, the details of this activity and the source of the copper bound by $\mathrm{Cn}$ Cbi1/Bim1 are not yet defined [5]. as chitin and chitosan, which form a highly cross-linked and rigid structure near the plasma membrane.

88 More superficial layers include other carbohydrates such as $\alpha$ - and $\beta$-glucans, as well as mannosylated proteins [8]. During infection and other periods of cell stress, Cryptococcus species remodel the cell wall to promote microbial survival under changing environmental conditions. During infection, these adaptive 
92 attachment of an antiphagocytic capsule, and masking immunogenic cell wall epitopes to avoid immune

93 recognition [9-12]. Several host-relevant signals are required for the induction of this type of fungal cell

94 wall remodeling, including host temperature and the relatively alkaline $\mathrm{pH}$ encountered during infection

$95[9,13]$. However, it is not well understood how metal stress and nutritional immunity responses affect

96 the fungal cell wall, or if the fungus actively remodels its cell surface in response to those stresses.

99 physiological importance to the microbe of metal chelation by the fungal cell wall is poorly understood.

100 To further explore the interaction between copper homeostasis and the fungal cell wall, we analyzed the

101 cell wall remodelling response in the cbi1s mutant strain, which is defective in a cell surface protein

102 involved in copper homeostasis. We first characterized the role of Cbi1 in the transcriptional signatures

103 of $C n$ cell wall-regulating genes. We also defined the physiological effects of mutations in proteins involved

104 in copper homeostasis on the composition and integrity of the cell wall. Since the Cn cell wall controls

105 macrophage activation, we determined how copper acquisition and homeostasis affect host innate

106 immune recognition signals as well as the expression of specific microbial phenotypes associated with

107 virulence. These studies suggest that copper availability affects the architecture and integrity of the fungal

108 cell wall; processes likely required for microbial adaptation to host-like nutrional environments. Based

109 upon our data we propose a dual role for the fungal cell wall in protecting $C$. neformans against the 


\section{Results}

113 The transcription factor Cuf1 regulates cell wall integrity in response to cellular copper levels through

114 the Cbi1-Ctr1 copper uptake complex

A recent study identified the $C$. neoformans Cuf1-dependent copper regulon in response to both copper deficiency and copper excess [4]. During copper deficiency, the most upregulated Cuf1-dependent transcripts represent genes involved in copper uptake, including those encoding for the high-affinity copper transporters Ctr1 and Ctr4 and the newly identified Cbi1 protein [4]. Previously referred to as $\mathrm{Cn}$ Bim1, this protein has been renamed Cbi1 to reflect its known biochemical activities [6, 7], and to recognize the previously described $\mathrm{Cn}$ Bim1 microtubule-binding protein involved in filamentous growth [16]. Other Cn Cuf1- and copper-regulated genes include many involved in cell wall synthesis and carbohydrate metabolism, potentially connecting copper homeostasis with cell wall remodeling [4, 5].

In pathogens, the fungal cell wall is a dynamic structure required for viability, stress resistance, morphogenesis and virulence. Its composition is actively remodeled in response to various stress signals, and this process is controlled by conserved signaling cascades, including the cell wall integrity (CWI) pathway [17]. The cell wall stress experienced by the copper homeostasis mutants, specifically during copper deprivation, is reflected in transcriptional alterations in the CWI pathway. The ROM2 gene encodes a guanine nucleotide exchange factor required for CWI pathway activation under conditions of cell stress [18]. Transcriptional induction of ROM2 is therefore typically observed during conditions of cell wall stress. Comparative transcriptional analysis of the WT and cuf1 $\triangle$ mutant revealed similar ROM2 transcript levels during copper sufficiency. In contrast, ROM2 transcript levels were 3-fold higher in the cuf1 $\triangle$ strain compared to wildtype during copper starvation, consistent with an accentuated sensing of cell wall stress in this strain in this condition. Complementation of the cuf1 $\triangle$ mutant with the CUF1-FLAG gene (cuf1 $\Delta^{c}$ strain) restored $R O M 2$ transcript to wildtype levels (Fig 1B). 
To further analyze the impact of CUF1 and other copper homeostasis genes for maintaining cell

wall integrity during copper deficiency, we assessed the sensitivity of the $\operatorname{cuf} 1 \Delta, \operatorname{cbi} 1 \Delta, \operatorname{ctr} 1 \Delta$ and $\operatorname{ctr} 4 \Delta$ strains to cell wall stressors in copper-replete and copper-deficient conditions. These stresses included calcofluor white (CFW, blocks chitin assembly), Congo red (impairs assembly of cell wall polymers, mainly chitin), caffeine (impacts PKA-mediated signal transduction), SDS (cell surface/ membrane stressor) and $\mathrm{NaCl}$ (osmotic stressor) [19-21]. We did not observe any growth phenotypes for the mutant strains in the presence of these cell wall stressors under copper-replete conditions (Supp Fig 1A). In contrast, during copper starvation induced by the extracellular copper (I) chelator bathocuproinedisulfonic acid (BCS) $(100 \mu \mathrm{M})$, the cuf1 $1 \Delta$ and cbi1 $\Delta$ strains exhibited strong growth inhibition compared to WT on $\mathrm{NaCl}$, SDS, Congo red and CFW-containing media (Fig 1B). Even at more modest levels of copper chelation $(10 \mu \mathrm{M}$ $\mathrm{BCS}$ ), the cuf1 $\Delta$ and cbi1 $\Delta$ strains exhibited strong growth inhibition on Congo red-containing media (Fig. 1C). Additionally, the Ctr1 copper transporter was similarly required for survival during copper deprivation in the presence of $\mathrm{NaCl}$ and CFW, but not in the presence of SDS. No cell wall stress-associated growth defect was noted for the $c t r 4 \Delta$ copper transporter mutant strain (Fig 1B), supporting prior observations that the Ctr1 and Ctr4 high affinity copper transporters serve overlapping but non-redundant functions in

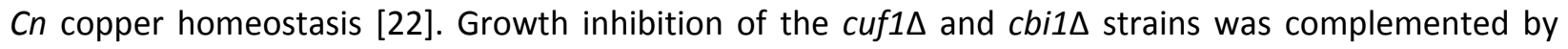
expressing epitope-tagged versions of these proteins in the respective mutant strains [Cuf1-Flag in cuf1 $\Delta$

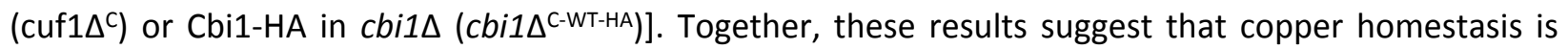
required for $C n$ cell wall stress resistance.

To further explore the relationships among the $C n$ copper homeostasis proteins in cell wall integrity, especially the less well-characterized Cbi1 protein, we conditionally overexpressed the CBI1 gene in a series of individual and double mutant strains (Fig 1C). Galactose-mediated overexpression of the pGAL7-CBI1 allele fully complemented the copper-dependent cell wall growth defect of the cbi1 mutant, and partially that of the cuf1 $\Delta$ strain. In contrast, overexpression of $C B I 1$ was unable to restore 
cell wall integrity to strains with a $\operatorname{ctr} 1 \Delta$ mutation. These results are consistent with prior studies suggesting that Cbi1 and Ctr1 are independent components of a copper transporter complex [5]. of cell wall integrity in the cuf1 $\Delta$ mutant.

We also assessed Cn copper-dependent cell wall integrity phenotypes using an alternative method of copper limitation to extracellular copper chelation by BCS. We incubated the $\mathrm{Cn}$ strains in media containing ethanol and glycerol as sole carbon sources. Growth on these non-fermentable carbohydrates is only supported by cellular respiration, effectively shunting intracellular copper into the mitochondria to the copper-dependent enzymes required for oxidative phosphorylation. Incubation of the WT and $c b i 1 \Delta^{c-W T}$ strains in YPEG $+0.01 \%$ SDS caused a $\sim 40 \%$ growth reduction, and an even more severe reduction of growth ( 90\%) in the cbi1s strain (Fig 1D). This growth impairment was complemented in all strains by supplementation with $\mathrm{CuSO}_{4}$, suggesting that shuttling of copper from

171 other pathways towards respiration influences the ability of $C n$ to withstand cell surface stress. Depletion of Cbi1 further decreased cell fitness under these conditions.

174 withinin the secretory pathway and subsequent altered metalation of secreted proteins $[2,23]$. A modest 175 growth defect on Congo red was observed for the $\operatorname{ccc} 2 \Delta$ strain, and the defect developed independent of 176 copper availability (Fig. 1E). These results suggest that defective copper loading of enzymes in the 177 secretory compartment is likely not the cause of the Cn cell wall phenotypes observed during copper 178 deficiency.

The Cfo1 ferroxidase is a copper-dependent enzyme involved in high-affinity iron acquisition [24].

180 Therefore, loss-of-function mutations in Cuf1 or other components of the Cn copper uptake machinery 181 would be predicted to affect intracellular iron concentrations as well as copper levels. Additionally, 
182

184

previous studies demonstrated that iron homeostasis is important for proper fungal cell wall and membrane architecture $[25,26]$. We therefore analyzed the effects of exogenous copper or iron on the BCS-induced cell wall phenotypes of the cbi1 $\triangle$ and cuf1 $\Delta$ mutants. Individual supplementation of the growth medium with copper, but not iron, restored growth to the cbi1 $\Delta$ and cuf1 $\Delta$ strains in the presence of cell wall stress and copper depletion (Fig 1F).

\section{Changes in Cn cell wall composition in response to defective copper homeostasis}

To further characterize the specific role of $\mathrm{Cbi1}$ in cell wall homeostasis during copper stress, we used transmission electron microscopy (TEM) to characterize the cell wall architecture of the wildtype (WT) and cbi1 $\Delta$ strains incubated in both copper-sufficient and copper-deficient growth conditions (Fig 2). In copper-sufficient conditions the Cn WT cell wall consists of two layers characterized by differing electron density [27-29]. Extracellular copper sequestration by the highly copper-specific chelator BCS resulted in decreased electron density in the innermost cell wall layer composed primarily of chitin and chitosan (Fig 2 A, C). These chito-oligomers efficiently bind bivalent metals (including copper ions), consistent with the higher electron density of this cell wall layer during copper sufficiency $[14,15]$. The cell wall of the cbi1 $\Delta$ mutant strain was similar to WT during copper sufficiency, displaying distinct layers based on electron density. However, the copper-starved cbi1 $\Delta$ strain demonstrated a reduction in total cell wall thickness compared to both the WT strain and the copper-sufficient cbi1 $\Delta$ cells (Fig 2B). Also in contrast to WT, there was no reduction in the inner cell wall electron density in the cbi1 $\Delta$ mutant strains during copper deficiency (Fig 2A, C). These results suggest a model in which Cbi1 is required for the release of cell wall-bound metals during copper starvation.

The ultrastructural changes observed in the cbi1 $\Delta$ strain cell wall during copper starvation were not due to altered cell viability. Although the $c b i 1 \Delta$ strain demonstrated a defect in proliferation during copper deficiency, we observed no decrease in cbi1 $\Delta$ cell viability during the first 24 hours, as assessed by 
205

206

207

208

209

210

211

212

213

214

215

216

quantitative cultures of colony-forming units (CFUs) (Supp Fig 1 B-C). We also assessed the effective "copper state" of the WT and cbi1 $\Delta$ strains in the conditions chosen for copper sufficiency $\left(10 \mu \mathrm{M} \mathrm{CuSO}_{4}\right)$ and deficiency $(250 \mu \mathrm{M}$ BCS) by quantifying transcript levels of the CMT1 metallothionein gene (induced during high copper states) and the CTR4 copper transporter gene (induced during copper starvation) (Supp Fig 1D). Both the WT and cbi1 $\Delta$ strains demonstrated a strong induction of CTR4 expression, but not of the CMT1 transcript, indicating that copper deficiency was induced by BCS treatment compared to the copper sufficient growth conditions. We also performed ICP-MS-based metal quantification of cellassociated copper and iron in each growth condition (Supp Fig $1 \mathrm{E}-\mathrm{F}$ ). A consistent and similar pattern of reduced cell-associated Cu was measured in the WT and cbi1 $\Delta$ cells cells incubated in BCS. Additionally, a decrease in iron levels was observed in copper-deficient cells, consistent with known copper-dependent iron uptake mechanisms in $\mathrm{Cn}$.

\section{Transcriptional changes in cell wall genes in response to copper status}

Prior investigations have established a set of $C$. neoformans genes encoding enzymes involved in the synthesis and chemical modification of the major cell wall structural carbohydrates. These include 8 chitin synthetase genes (CHS1-8), 4 chitin deacetylase genes (chitin-to-chitosan conversion) (CDA1-3, FPD1), and the chitin synthase regulator-2 (CSR2). Genes involved in glucan synthesis include KRE6 and SKN1 ( $\beta$-1,6-glucan), FKS1 ( $\beta$-1,3-glucan) and AGS1 ( $\alpha$-1,3-glucan) [8]. To investigate how copper availability and Cbi1 might affect cell wall carbohydrate homeostasis, we measured transcript levels of these major cell wall synthesis genes in copper deficient wildtype (WT), cbi1 $\Delta$ mutant, and $c b i 1 \Delta^{c-W T}$ complemented strain (Fig 2 D-E). Among the genes involved in chitin and chitosan synthesis, we observed significant increases in transcript abundance in the cbi1 $\triangle$ mutant for CHS6 ( 7 fold), CHS3 ( 4 fold) and CSR2 ( 3 fold), while the chitin/chitosan deacetylase genes CDA2 and FPD1 were downregulated (Fig 2D). In addition to genes involved in chitin/chitosan biosynthesis, the transcript level of the $\beta$-1,3-glucan 
synthase FKS1 gene was induced 8-fold. Changes in the expression of KRE6 ( $\beta$-1,6-glucan synthesis) and AGS1 ( $\alpha-1,3$-glucan synthesis) were not statistically significantly altered (Fig $2 \mathrm{E}$ ). Taken together, these findings indicate that the copper-deficient $c b i 1 \Delta$ strain displays transcriptional changes in several cell wall polysaccharide synthesis genes, especially those associated with chitosan and $\beta-1,3$-glucan synthesis. function of copper availability, we quantified $\beta$-glucan and chitin/chitosan levels in the WT, cbi1 $\Delta$ mutant, and $c b i 1 \Delta^{c-W T}$ complemented strains after incubation for $24 \mathrm{~h}$ in copper-sufficient (YPD $+10 \mu \mathrm{M} \mathrm{CuSO}{ }_{4}$ ) and copper-deficient (YPD $+250 \mu \mathrm{M}$ BCS) conditions. No significant changes were detected in total cell wall $\beta$-glucan between the WT and cbi1s cells in either growth condition (Supp Fig 2A). However, the cbi1 $\Delta$ mutant exposed to copper-deficiency displayed a greater than $50 \%$ reduction in total cell wall chitin and in chitosan compared to WT and complemented strains (Fig 3 A-B). These results are consistent with reduced transcript levels for the CDA2 and FPD1 chitin deacetylase genes in the copper-starved cbi1 strain. Therefore, the reduction of cell wall thickness and altered cell wall integrity in the cbi1 $\Delta$ strain during copper starvation is, in part, likely due to a reduction in the inner cell wall chito-oligomer layer. microscopy using chitin- and chitosan-specific fluorescent stains. We double-stained Cu-sufficient and Cudeficient WT, cbi1 $\Delta$ and $c b i 1 \Delta^{c-W T}$ cells with Calcofluor white (CFW), a small molecule globally staining chitin, and AlexaFluor488-conjugated wheat germ agglutin (WGA-Alexa 488), a lectin that binds exposed chito-oligomers. To a similar extent as in the biochemical chitin assays, we observed a reduction in CFW

247 staining intensity of Cu-deficient cbi1 $\Delta$ cells (Fig 3 C, Supp Fig 2B). WGA staining of WT and $c b i 1 \Delta^{c-W T}$ 248 complemented cells only revealed exposed chito-oligomers, primarily at regions of cell separation, 249 budding sites, and bud scars (Fig $3 \mathrm{C}$ ). In contrast, the copper-deficient cbi1 $\triangle$ cells demonstrated an 250 enrichment of WGA-Alexa 488 staining globally around the cell surface. We additionally stained cells with 251 EosinY, a small molecule that binds to chitosan polymers. Consistent with the biochemical data indicating 
252 reduced chitosan levels, we observed decreased EosinY staining intensity in copper-starved cbi1 $\Delta$ cells

253 (Fig 3D, Supp Fig 2 C-D).

We also performed flow cytometry on CFW and WGA-Alexa 488 stained cells to more precisely quantify the altered chito-oligomer staining pattern in these strains (Fig $3 \mathrm{E}-\mathrm{H}$, Supp Fig $2 \mathrm{E}-\mathrm{F}$ ). We directly compared WGA-Alexa 488 staining intensity to CFW staining intensity to assess chito-oligomer exposure relative to total cell wall chito-oligomer content. In copper-sufficient growth conditions, there was a small but statistically significant decrease in WGA-Alexa 488 staining intensity among the cbi1 $\Delta$ cells compared to WT and complemented strains. However, we observed a notable increase in relative WGA staining in a sizable subpopulation of cbi1s cells ("High WGA", Fig 3 G-H, Supp Fig 2E) during copper-starvation, consistent with the fluorescent microscopy results. Together, these findings suggest that the cell wall chito-oligomers of copper-deficient cbi1 $\Delta$ cells are not only decreased in total amount, but they are deposited within the cell wall in an aberrant manner, leading to a higher degree of exposure.

To explore the role of chitin and chitosan for modulating the resistance to copper stress, we assessed the growth effects during low and high copper stress for strains with mutations in either copper homeostasis or chitosan synthesis (Fig 4). As previously described, we observed poor growth of the cbi1s and $\operatorname{ctr} 1 \Delta$ strains during copper deficiency (Fig 4B). In line with previous findings, no sensitivity to copper starvation was observed for the $c t r 4 \Delta$ copper transporter mutant strain [30]. These results indicate that the Cbi1/Ctr1 complex can likely compensate for the loss of Ctr4, but that the Ctr4 transporter is not sufficient to maintain $\mathrm{Cn}$ growth during copper starvation in the absence of Ctr1. A slight reduction in

271 growth was observed for the chs3 $\Delta$ strain during copper starvation. Since Chs3 is responsible for the 272 synthesis of most of the chitin destined to be converted to chitosan, this result suggests that reductions 273 in chitosan may affect the ability of $\mathrm{Cn}$ to withstand low copper stress. No growth phenotype was 274 observed for the $c d a 2 \triangle$ chitin deacetylase gene, indicating that the observed dysregulation of $C D A 2$ in the $c b i 1 \Delta$ background does not explain the cbi1 $\Delta$ growth defect during copper deficiency. 
To assess the role of the chitin and chitosan inner layer on resistance to copper toxicity, we tested

277 the chs3 $\Delta$ and $c d a 2 \Delta$ mutant strains for growth phenotypes in the presence of increasing copper

278 concentations. The chitosan-deficient chs3 $\Delta$ strain was more sensitive to high copper stress than the wild-

279 type, and similar in its copper sensivity to strains with mutations in the $\mathrm{Cn}$ metallothionein genes CMT1

280 and $C M T 2$ that mediate scavenging of excess copper (Fig 4C). In contrast to $c h s 3 \Delta$, the $c d a 2 \Delta$ strain, with

281 a mutation in a single chitin deacetylase gene but relatively preserved cell wall chitosan levels,

282 demonstrated resistance to toxic copper levels compared to WT. The cbi1 $\Delta$ mutant displayed a similar

283 copper resistance profile as the $c d a 2 \Delta$ strain. This increased copper resistance was not shared with the

$284 \operatorname{ctr} 1 \Delta$ or $\operatorname{ctr} 4 \Delta$ copper transporter mutants, suggesting that altered copper transport was not responsible

285 for this phenotype. This finding suggests an unexpected new role for Cbi1 in modulating growth during

286 high copper stress, potentially by its known role in modulating CDA2 function.

Cell wall changes in response to low copper stress lead to increased macrophage activation and altered caspofungin tolerance

We tested the physiological relevance of altered copper homestasis to other infection-related processes involving the cell wall. C. neoformans strains with enhanced exposure of cell wall chitothe physiological consequences of the aberrant cbi1 $\Delta$ cell wall structure in host cell interactions, we coincubated C. neoformans strains with murine bone marrow-derived macrophages (BMM), assessing TNF- $\alpha$ production as a marker of host immune cell activation. Macrophages exposed to copper-deficient cbi1 $\Delta$ cells showed a statistically significant increase in TNF- $\alpha$ secretion compared to macrophages co-incubated 

host cell interactions and antifungal drug activity.

\section{Depletion of Cbi1 affects several cell wall-associated virulence factors.}

The Cryptococcus cell wall is not only important for stress resistance and modulating immune

317 alkaline $\mathrm{pH}$ and micronutrient limitation [11]. Strains with mutations in several chitin deacetylase genes,

318 in particular with a cda2 deletion, typically display enlarged capsules [21]. Similarly, the $c b i 1 \Delta$ mutant, in

319 which CDA2 levels are reduced, produced more surface capsule, especially in copper limiting conditions 
We performed scanning electron microscopic (SEM) analysis of WT and cbi1s cells after $3 \mathrm{~d}$ of capsule induction in the absence and presence of $250 \mu \mathrm{M}$ BCS (Fig 5F) to further analyze the role of Cbi1 in capsule architecture with a higher topographical resolution. Similar to capsule assessment by India ink counterstaining, we observed the most notable alterations in the capsular structure of the cbi1 $\Delta$ strain

325 during copper limitation. Under normal capsule-inducing conditions both strains showed typical capsule architecture with a more dense inner zone and a less dense outer layer with extended capsule fibers [36]. However, when copper deficiency was induced by BCS supplementation, the cbi1 $\triangle$ capsule displayed denser and more interconnected polysaccharide fibers compared to WT, with fewer freely extending individual capsule fibers.

Both copper limitation and cell wall alterations are important for the regulation of melanin, a cell wall-associated antioxidant pigment $[23,29]$. Melanin production itself is tightly linked to cellular copper levels since the rate-limiting phenoloxidase enzyme involved in melanin synthesis, laccase-1 (Cn Lac1), is functionally dependent on copper [37]. The cbi1s strain displayed defective melanin production on LDOPA containing media (Fig $5 \mathrm{C}$ ). The restoration of normal melanin production by the addition of $5 \mu \mathrm{M}$ $\mathrm{CuSO}_{4}$ is consistent with the known defects in copper acquisition in this strain [5]. We did not observe altered melanin production for the $\operatorname{ctr} 1 \Delta$ or $\operatorname{ctr} 4 \Delta$ strains, suggesting that the degree of intracellular copper limitation is greater in the absence of of the Cbi1 protein than in either of the single copper transporter mutants. Also, chitosan is required for the attachment of melanin to the cell surface and strains completely lacking chitosan display a "leaky melanin phenotype" in which melanin diffuses from

340 the cell into the growth medium [21]. Even though depletion of Cbi1 affects cell wall chitosan levels during 341 copper deficiency, we did not observe a leaky melanin phenotype. This is consistent with a reduction but 342 not the complete absence of chitosan in the cbi1s strain. Together these results suggest that Cbi1343 mediated cell wall remodeling and copper homeostasis affect the establishment of several cell wallassociated virulence factors. 


\section{Discussion}

In these experiments we demonstrated that copper deficiency, and either deletion of the Cuf1 transcription factor or the copper-binding Cbi1 cell surface protein, renders C. neoformans more susceptible to cell wall stress. This central result suggests that copper homeostasis mechanisms affect the integrity of the fungal cell wall. In turn, we demonstrated that genes involved in cell wall chitosan biosynthesis modulate resistance to copper stress. Furthermore, we characterized the biochemical and physiological changes that occur in the cryptococcal cell wall in response to low copper availability. These changes include a reduction in the amount of chitin and chitosan, two structurally related carbohydrates altered in the cbi1 mutant include an increased accumulation of surface capsule and a reduction in melanin, two mediators of virulence in this human fungal pathogen. Given the established role of the $\mathrm{Cn}$

357 cell surface to mediate immune avoidance, we documented altered interaction of the cbi1 $\Delta$ mutant with macrophages, indicating that these cell wall changes influence the ways in which $\mathrm{Cn}$ interacts with host innate immune cells.

Copper regulation by the infected host is an important mechanism of immune response to invading pathogens. In contrast to the well-described "nutritional immunity" that primarily involves the sequestering of other essential micronutrients such as iron and zinc away from infecting microorganisms, the host regulation of copper involves a complex coordination of copper sequestion in certain tissues and the induction of very high copper levels in other sites [3, 22, 38, 39]. In this way, microbial pathogens must be able to acquire sufficient copper for cell metabolism and energy production while simultanesously preventing the harmful effects of host-induced copper toxicity. In C. neoformans, the Cuf1 transcription

367 factor controls this cellular response to both low and high copper concentrations [2, 4]. In contrast, many other fungal species, both pathogens and nonpathogens, utilize distinct transcriptional regulators for each of these copper states. A genome-wide analysis identified many new and novel copper- and Cuf1- 
regulated genes, likely reflecting the wide range of copper concentrations encountered by this fungal

371 pathogen in its varied environmental niches [4].

In response to high copper stress, microorganisms have developed multiple means of copper

detoxification, including copper efflux systems as well as the induction of the copper-binding

metallothienein proteins $[2,39]$. In $C$. neoformans, expression of the CMT1 and CMT2 metallothionein

genes is controlled by Cuf1 in response to elevated copper levels, and these genes are required for fungal

mechanism against the effects caused by high copper stress is the up-regulation of the ATM1 gene, wall remodelling in response to copper stress, specifically by altering the cell wall chitin/chitosan layer. 
and the simultaneous re-localization of the copper-independent Sod2 protein to maintain cellular antioxidant defense levels during copper limitation [45].

Based on our findings we suggest a model in which the fungal cell wall serves two functions relevant to copper homeostasis. First, under conditions of copper excess, cell wall carbohydrates bind copper ions to prevent cytotoxic copper stress. Second, under conditions of copper deficiency, the cell wall releases bound copper to metal transporters for maintenance of cell homeostasis. Our data also suggest that the Cbi1 protein is one component of this copper acquisition process between the Ctr1 401 copper transporter and the fungal cell wall. CBI1 and CTR1 are among the Cn genes with the highest 402 degree of regulation by the copper-sensing Cuf1 transcription factor in conditions of Cu depletion [4, 5].

403 The Cbi1 and Ctr1 proteins interact both physically and genetically [5]. Accordingly, the $c b i 1 \Delta$ and $\operatorname{ctr} 1 \Delta$ 404 mutants display some similar phenotypes: poor growth in the presence of copper deprivation and cell wall 405 stress.

407 in Ctr1-mediated copper transport into the cell. The cbi1s strain has a more severe, but copper408 remediable, melanin production defect than the $\operatorname{ctr} 1 \Delta$ strain, suggesting a greater degree of intracellular 409 copper limitation or altered copper acquisition. Moreover, only the $c b i 1 \Delta$ mutant, and not the $\operatorname{ctr} 1 \Delta$ or $410 \quad c t r 4 \Delta$ copper transporter mutants, displayed enhanced resistance to toxic copper levels. These results 411 begin to elucidate a new role for cell wall polysaccharides in adaptation to environmental changes. Since 412 cell wall polysaccharides such as chitin and chitosan are known to avidly bind divalent metal ions such as $413 \mathrm{Cu}^{2+}$, it is likely that their presence in the fungal cell wall serves to similarly bind copper encountered in 414 the environment. At lower levels of copper exposure, cell wall-associated copper might provide a readily 415 accessible storage site for the copper transporter complexes. At higher levels of copper, polymers such as 
chitosan might bind copper, protecting the cell body and membranes against the toxic effects of free $\mathrm{Cu}^{2+}$

417 ions. complex carbohydrate surfaces and promote further structural alterations by specific hydrolases [46]. LPMOs have been best explored in the context of degradation of crystalline cellulose and chitin [47]. We

421 have previously demonstrated that Cbi1 binds copper, but it lacks the redox activity that defines the LPMO

422 class of enzymes $[5,6]$. Its copper-binding activity, and its physical association with the Ctr 1 protein, 423 suggest that Cbi1 might act as an intermediary to shuttle copper from the cell wall storage sites to the 424 copper importer system. Our TEM data here support this model. In these images the electron density of 425 the chitin/chitosan cell wall layer remains unchanged in the cbi1 $\Delta$ mutant during extracellular copper 426 starvation. In contrast, the electron density of this layer in WT cells decreases during copper starvation, 427 consistent with enhanced cellular import of this metal ion mediated in part by Cbi1. changes in cell wall genes, and that these transcriptional changes result in functional consequences for the $\mathrm{Cn}$ cell wall. These changes include reduced levels of chitin and chitosan as well as altered cell wall 431 architecture, especially in the presence of copper limitation. As a result, cell wall-associated virulence 432 factors are altered in function, resulting in changes in the interaction with host immune cells. The specific 433 activity of the Cbi1 protein has yet to be determined. Also, it is not yet clear whether the cell wall changes 434 in the cbi1 $\Delta$ strain are directly related to Cbi1 function or whether they represent compensatory cellular 435 changes in response to stress. This type of cell wall adaptation to cell stress is commonly observed in other 436 conditions [48]. For example, cell wall chitin levels are increased in the human fungal pathogens 437 Aspergillus fumigatus and C. neoformans during treatment with the beta-glucan synthase inhibitor capofungin [33]. Blunting this adaptive cell wall chitin response renders these cell more susceptible to the 
activity of this antifungal agent. Similarly, we demonstrated here that the cbi1 $\Delta$ mutation, and its downstream defective chitin response, results in a similar degree of enhanced caspofungin susceptibility as mutation in chitin synthesis genes themselves.

Our observations of significant reductions in cell wall chitosan in the copper-starved cbi1 $\Delta$ strain also suggest that this cell wall polymer may contribute to copper homeostasis. In contrast to many ascomycete fungal pathogens, $C$. neoformans contains much more chitosan in the inner chito-oligomer layers of the cell wall [8]. Chitosan is a relatively de-acetylated form of chitin. Both chitin and chitosan exist in varying sizes, the polymer length determined by both endogenous and exogenous synthases and chitinases. In fact, the size of the chitin and chitosan molecules, as well as their relative degrees of acetylation/deacetylation, determine their immunogenicity. Therefore, both host and microbe possess intricate means to regulate chito-oligomer molecular size and acetylation status $[8,13,49]$.

In C. neoformans, four putative chitin deacetylases contribute to the conversion of chitin to chitosan: Cda1, Cda2, Cda3, and Fpd1. Prior mutational analysis revealed that a Cn cda1,2,3 triple mutant is devoid of most measurable cell wall chitosan during vegetative growth [21]. Although the Fpd1 enzyme is not required for chitosan conversion from chitin under normal growth conditions, it may contribute to the further deacetylation of pre-formed chitosan [50]. Consistent with the decrease of cell wall chitosan in the cbi1s mutant, we identified two of the four chitin deacetylase genes, cda2 and fpd1, to be downregulated in copper-deficient cbi1 $\Delta$ cells. Hence, Cda2 and Fpd1 may be involved in regulating cell wall chitosan levels in response to cellular copper levels. Notably, cda2 was previously identified as a Cuf1regulated gene [4], which further strengthens the connection between cell wall chitosan and copper homeostasis. Therefore, Fpd1 together with Cda2 could potentially be involved in modulating the deacetylation ratio of chitosan molecules, and by doing so modulating the copper binding capacity of the aggregate cell wall sugar polymers in response to changing copper levels. 

triggering immune activation and defense mechanism. Therefore, masking chitin is one important tool to evade immune defense. One strategy for dampening the immune recognition of chitin is its deacetylation to form chitosan [49]. Our cell wall analysis revealed a complex set of changes in response to copper

466 homeostasis and the cbi1 $\Delta$ mutation. Although the total levels of chitin and chitosan were decreased in

467 the $c b i 1 \Delta$ strain, the degree of exposure of these cell wall sugars was greater in this strain compared to 468 WT. Similar alterations in chitin/chitosan exposure have been shown to fundamentally alter the degree of 469 immunological masking of fungal cells from recognition by host immune cells. In fact, there was a striking 470 correlation between the degree of exposed chitin/chitosan exposure (as measured by WGA Alexa488 471 staining) and the activation of a macrophage TNF- $\alpha$ response in fungal co-culture $[13,32]$. Also, lectins

472 and monocolonal antibodies that block chitin recognition have been proposed as adjunctive therapeutic 473 strategies for cryptococcosis and other fungal infections [51].

475 during conditions associated with human infection, including both high and low copper levels. In this way,

476 the cell wall serves as both storage site for copper during low copper levels, as well as a copper-binding 477 organelle to prevent excessive intracellular accumulation during copper toxicity. We have further defined 478 cellular roles for a unique copper-binding protein that serves to mediate copper transfer between the 479 fungal cell wall and copper import proteins.

$481 \quad$ Material and Methods

Strains, media and growth conditions 
neoformans by biolistic transformation [52]. Yeast extract (2\%)-peptone (1\%)-dextrose (2\%) (YPD) medium supplemented with $2 \%$ agar and $100 \mu \mathrm{g} \mathrm{ml-1}$ of nourseothricin (NAT), $200 \mu \mathrm{g} \mathrm{ml}-1$ of neomycin (G418) or $200 \mu \mathrm{g} \mathrm{ml-1} \mathrm{of} \mathrm{hygromycin} \mathrm{B} \mathrm{(HYG)} \mathrm{was} \mathrm{used} \mathrm{for} \mathrm{colony} \mathrm{selection} \mathrm{after} \mathrm{biolistic} \mathrm{transformation.}$ Cloning strategies as well as plasmids and oligos used for creation of Cryptococcus transformation contructs are described in Supp Table 2-3. Transformants were screened by PCR and Southern blot for intended mutations. Cbi1-HA expression among relevant transformants was confirmed by western blot. or the $\mathrm{Cu}^{+}$chelator bathocuproine disulfonate (BCS), respectively. Alternatively, to BCS supplementation, strains were cultivated in Yeast extract-peptone medium supplemented with 3\% Glycerol and 2\% Ethanol (YPEG). For galactose-regulated expression induction, $\mathrm{SC}+2 \%$ Galactose (SC-Gal) or SC+2\% Glucose (SCGlu) was used and supplemented as indicated. To analyze cell wall associated phenotypes, caffeine (0.5 medium plates, a 6 -fold serial dilution, starting at $\mathrm{OD}_{600} 0.25$, of strains was spotted and incubated for indicated time and temperature. For assessment of melanization, overnight cultures in YPD were washed once in PBS and resuspended in PBS to $\mathrm{OD}_{600}$ 2.5. Next, 5 to $10 \mu \mathrm{L}$ of the resuspended culture were spotted onto L-3,4-dihydroxyphenylalanine (L-DOPA) media (7.6 mM L-asparagine monohydrate, $5.6 \mathrm{mM}$ glucose, 
For ROM2 transcript analysis C. neoformans overnight cultures grown in synthetic complete (SC) medium

510 (MP Biomedicals) were diluted to $\mathrm{OD}_{600} 0.3$, and cultures were supplemented and cultivated as indicated.

511 For cell wall synthesis genes transcript analysis and copper status analysis, C. neoformans overnight

512 cultures grown in YPD medium were diluted to $\mathrm{OD}_{600} 0.05$, supplemented as indicated and cultivated for

$51324 \mathrm{~h}$ at $30^{\circ} \mathrm{C}$. For RNA extraction, cells were cultivated as indicated. Cultures were harvested, washed $1 \mathrm{x}$

514 with PBS and flash frozen on dry ice, followed by lyophilization. RNA was extracted using the RNeasy Plant

515 Mini Kit (Qiagen) with optional on-column DNAse digestion. cDNA for real time-PCR (RT-PCR) was

516 prepared using the Iscript cDNA synthesis kit (Biorad). For RT-PCR, cDNA was diluted 1:5 in RNase-free

517 water, added to ITAQ Universal SYBR Green Supermix (Bio-Rad) per protocol instructions and analyzed on

518 a CFX384 C1000 ThermoCycler (BioRad, ROM2 analysis and Cu status analysis). For analysis of cell wall

519 transcripts, the diluted RNA was mixed with the PowerUP SYBR Green Master mix (applied biosystems)

520 per protocol instruction and analyzed on a QuantStudio 6 Flex (applied biosystems). Oligos used for qRT-

521 PCR analysis are shown in Supp Table 3. $C_{\mathrm{T}}$ values were determined using the included CFX Maestro

522 software (BioRad) or the QuantStudio 6 Flex, respectively. Gene expression values were normalized to

523 the housekeeping gene GAPDH and expression fold changes determined by the $\Delta \triangle \mathrm{C}_{\mathrm{T}}$ method. For all qRT-

524 PCR studies, a minimum of 3 independent biological replicates were used for the analysis of mRNA

525 expression changes.

526

527 Inductively coupled plasma mass spectrometry (ICP-MS)

528 Cell associated metals ( $\mathrm{Fe}$ and $\mathrm{Cu}$ ) were quantified from lyophilized yeast. In short, yeast cells were treated

529 as indicated, spun down and washed $2 x$ with ICP-MS grade water. In the last wash step, cell were counted,

530 spun down and lyophilized. Samples were digested in $300 \mathrm{uL} 50 \%$ ICP-MS grade Nitric Acid for $1 \mathrm{~h}$, at $90^{\circ} \mathrm{C}$

531 and cooled down overnight at RT. Metal content was analyzed by ICP-MS at the Oregon Health Sciences

532 University elemental analysis facility on an Agilent 7700X ICP-MS. 


\section{Liquid growth assays}

All liquid growth analysis were performed in 96 well plates. For the growth analysis in YPEG in the presence of the surface stressor SDS, overnight cultures $\left(\mathrm{YPD}, 30^{\circ} \mathrm{C}\right)$, were harvested and washed $1 \mathrm{x}$ with YPEG and then normalized to $\mathrm{OD}_{600} 2.0$ (in YPEG). Growth media was supplemented as indicated and filled into 96 well plate (195 $\mu \mathrm{L}$ each well). Wells were inoculated with $5 \mu \mathrm{L}$ of indicated strain (final $\mathrm{OD}_{600}=0.05$ ). Plates were covered with a semipermeable membrane (Breathe-Easy, Diversified Biotech) and incubated at $30^{\circ} \mathrm{C}$ with shaking at $1150 \mathrm{rpm}$ in a Finstruments shaker instrument. Growth graphs of the indicated strains at the conditions analyzed were generated by plotting the $\mathrm{OD}_{600}$ readings normalized to WT-YPEG growth at the $24 \mathrm{~h}$ time point. Three biological replicates were performed.

For minimal inhibitory concentration analysis (MIC), overnight cultures $\left(\mathrm{SC}, 30^{\circ} \mathrm{C}\right)$, were harvested and washed $1 x$ with PBS and then set to $\mathrm{OD}_{600} 0.25$ (in PBS) and stored on ice until further usage. $2 \mathrm{x}$ concentrated working stocks of caspofungin were prepared in SC medium (final concentration in assay ranged 100 to $0.78 \mu \mathrm{g} / \mathrm{mL}$ ). Cells were diluted 1:100 in either SC or SC+200 $\mu \mathrm{M}$ BCS (final concentration in assay $100 \mu \mathrm{M}$ BCS). In 96 well plate, $100 \mu \mathrm{L}$ of diluted cells were mixed with $100 \mu \mathrm{L}$ of $2 x$ concentrated caspofungin stocks. The plate was covered with a semipermeable membrane (Breathe-Easy, Diversified Biotech) and incubated at $30^{\circ} \mathrm{C}$ with shaking at $1150 \mathrm{rpm}$ in a Finstruments shaker instrument for $24 \mathrm{~h}$. Growth graphs of the indicated strains at the conditions analyzed were generated by calculating the relative growth of the drug-treated condition in relation to the untreated condition (drug-treated OD600/untreated OD600). Four biological replicates were performed.

\section{Transmission electron microscopy (TEM)}

Overnight cultures $\left(\mathrm{YPD}, 30^{\circ} \mathrm{C}\right)$ were harvested and washed $1 \mathrm{x}$ with YPD. Indicated strains were inoculated to an $\mathrm{OD}_{600}$ of 0.05 in $50 \mathrm{~mL} \mathrm{YPD}+10 \mu \mathrm{M} \mathrm{CuSO}_{4}$ (=Cu sufficiency) or $250 \mu \mathrm{M} \mathrm{BCS} \mathrm{(=Cu} \mathrm{deficiency)} \mathrm{and}$ cultivated for $24 \mathrm{~h}$ at $30^{\circ} \mathrm{C}$. In the following day, 50 to $100 \mu \mathrm{L}$ of the culture were harvested and washed 
$1 x$ with PBS. Next, cells were pelleted and overlayed with fixative (4\% formaldehyde, $2 \%$ Glutaraldehyde

558

559

560

561

562

563

564

565

566

567

568

in PBS) and incubated for $4 \mathrm{~h}$ at RT. Then, fixative was removed, and the sample was washed twice with $1 x$ PBS, with a 10 minute incubation time at RT in between wash steps. After last washing step, the PBS was removed and $1 \% \mathrm{OsO}_{4}$ was added to the sample to complete cover. The tube is sealed and incubated for $1 \mathrm{~h}$ at $\mathrm{RT}$ in the dark. Then the $\mathrm{OsO}_{4}$ was removed, and the sample rinsed with $1 \mathrm{x}$ PBS, 2 times for at least 10 minutes each time (RT). After last PBS rinse, residual PBS was removed and sample was rinse with $0.1 \mathrm{~N}$ acetate buffer, 1 time at least 10 minutes each time (RT). The acetate buffer was removed, and the sample was stained with $0.5 \%$ uranyl acetate (UA) for one hour, RT. Once staining is complete, the uranyl acetate was removed and the sample rinsed with $0.1 \mathrm{~N}$ acetate buffer, 2 times at least 10 minutes each time. In the next steps the samples were dehydrated in several ethanol incubation steps by rinsing twice, at least 10 minutes each time, with 30\% Ethanol, 50\% Ethanol, 70\% Ethanol and 90\% Ethanol. Finally, the sample were rinsed 3 times, at least 10 minutes each time, with 100\% Ethanol.

Once the dehydration was complete, ethanol was removed and the dehydrated sample was embedded into resin $(53,5 \%(w / v)$ resin, $20.5 \%(w / v)$ DDSA, $26 \%(w / v)$ NMA, $1.4 \%(v / v)$ DMP-30). The sample were incubated in resin mix at RT overnight. The following day, samples were incubated at 50$60^{\circ} \mathrm{C}$ for 10 minutes, the old resin mix was replaced by freshly made resin mix and incubated for 10 mins at $\mathrm{RT}$, followed by 10 minutes at at $50-60^{\circ} \mathrm{C}$. This resin wash step was repeated one more time, followed by a $48 \mathrm{~h}$ incubation at $50-60^{\circ} \mathrm{C}$. The embedded samples were cut into $70 \mathrm{~nm}$ thick sections on an Ultracut microtome and placed on TEM grids. The sections were counterstained with uranyl acetate and lead citrate and then imaged on an FEI Technai G2 Twin transmission electron microscope. Cell wall thickness was measured using Image (Cu sufficient WT: 8 cells, Cu deficient WT: 7 cells, Cu sufficient cbi1 $\Delta: 14$ cells

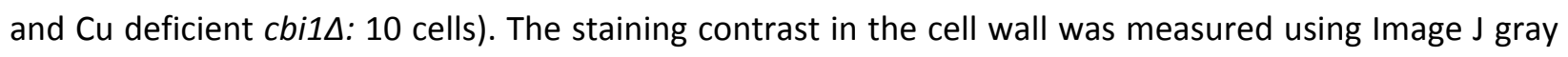
scale measurement tool. 


\section{Scanning electron microscopy (SEM)}

581

Overnight cultures $\left(\mathrm{YPD}, 30^{\circ} \mathrm{C}\right.$ ) were harvested and washed $1 \mathrm{x}$ with PBS. Indicated strains were inoculated to an $\mathrm{OD}_{600}$ of 0.1 in $25 \mathrm{~mL} \mathrm{CO}$-independent medium (Gibco) or $25 \mathrm{~mL} \mathrm{CO}_{2}$-independent medium supplemented with $250 \mu \mathrm{M} \mathrm{BCS}$ and cultivated for $3 \mathrm{~d}$ at $37^{\circ} \mathrm{C} .5 \mathrm{~mL}$ of each culture were harvested, checked for capsule formation by India ink stain and washed $3 \mathrm{x}$ with PBS (without calcium and magnesium). Cells were fixed for $1 \mathrm{~h}$ at RT, using $2.5 \%$ glutaraldehyde in PBS and washed 3 times with PBS and checked for intact capsule by india ink staining. Then, cells were mounted onto poly-L-lysine- coated coverslips (Neuvitro, 12mm, \#1 thickness coverlsips) and incubated for $20 \mathrm{~min}$ at RT. After mounting, cells were sequentially dehydrated in several ethanol washes $(1 \times 30 \%, 1 \times 50 \%, 1 \times 70 \%$, each 5 min RT, followed by $1 \times 95 \%$ and $2 \times 100 \%, 10$ min RT). After dehydration mounted cells were stored in $100 \%$ ethanol until the critical point drying. Cell samples were critical point dried with a Tousimis 931 critical point dryer (Rockville, Maryland) and coated with gold-palladium using a Cressington 108 sputter-coater (Watford, United Kingdom). Samples were mounted and imaged on a Hitachi S-4700 scanning electron microscope (Tokyo, Japan).

\section{Cell wall isolation and analysis}

Overnight cultures $\left(\mathrm{YPD}, 30^{\circ} \mathrm{C}\right)$ were harvested and washed $1 \mathrm{x}$ with YPD. Indicated strains were inoculated to an $\mathrm{OD}_{600}$ of 0.05 in $50 \mathrm{~mL}$ YPD $+10 \mu \mathrm{M} \mathrm{CuSO}_{4}$ (=Cu sufficiency) or $250 \mu \mathrm{M} \mathrm{BCS} \mathrm{(=Cu} \mathrm{deficiency)} \mathrm{and}$ cultivated for $24 \mathrm{~h}$ at $30^{\circ} \mathrm{C}$. The following day, 10 to $25 \mathrm{~mL}$ of the cells were harvested and washed twice with $\mathrm{dH}_{2} \mathrm{O}$. In the last wash step, cells were counted, spun down and lyophilized. Chitin and chitosan levels were quantified from lyophilized yeast using a modified MBTH (3-methyl-benzothiazolinone hydrazine hydrochloride) method as previously described [13]. $\beta$-glucan was quantified using the megazyme yeast $\beta$-glucan kit. In short lyophilized yeast were milled using glass beads, resuspended in $800 \mu \mathrm{L} 2 \mathrm{M} \mathrm{KOH}$ and 
603

604

605

606

607

608

609

610

611

612

transferred into a new $12 \mathrm{ml}$ reaction tube and stirred for 30 mins in an ice water bath. Then, $3.2 \mathrm{~mL}$ of 1.2 M sodium acetate $\mathrm{pH} 8.3$ and $40 \mu \mathrm{L}$ glucazyme was added and the sample stirred for $2 \mathrm{~min}$. The sample was transferred to a $15 \mathrm{~mL}$ screw cap tube and incubated $\mathrm{ON}$ at $40^{\circ} \mathrm{C}$ in a water bath. The next day, $10 \mathrm{~mL}$ $\mathrm{dH}_{2} \mathrm{O}$ was added to the samples, mixed thoroughly and centrifuged for 10 mins at $3000 \mathrm{rpm}$. Then, 100 $\mu \mathrm{L}$ of the supernatant was mixed with GOPOD reagent and incubated for 20 mins at $40^{\circ} \mathrm{C}$ in a water bath. $2 \times 200 \mu \mathrm{L}$ of each sample were transferred into a 96 well plate and read (against reagent blank) at 510 $\mathrm{nm}$. A standard curve was prepared using the manufacturer's supplied D-glucose standard solution and mg glucose was calculated using equation provided by manufacturer. Measured values were normalized by cell count.

\section{Cell wall staining and flow cytometry}

Prior to analysis cells were treated as indicated. To visualize chitin, cells were harvested and stained with $100 \mu \mathrm{g} / \mathrm{ml}$ Alexa488-conjugated wheat germ agglutinin (WGA, Molecular Probes) for 35 minutes in the dark, RT, followed by $25 \mu \mathrm{g} / \mathrm{ml}$ calcofluor white (CFW, Fluka Analytical) for 10 minutes, RT. After staining, cells were washed $2 x$ with PBS and were resuspended in 20-50 $\mu \mathrm{L}$ PBS for microscopic analysis. Alexa488-WGA was imaged using a GFP filter and CFW was imaged using a DAPI filter. For flow cytometry, cells were Alexa488-WGA and CFW stained as previously described, washed $2 x$ with PBS and set to $10^{6}$ cells (in $1 \mathrm{~mL}$ PBS). Alexa488-WGA stained cells were analyzed using a $488 \mathrm{~nm}$ laser and CFW cells were analyzed using a $405 \mathrm{~nm}$ laser. The FACS analysis was performed at the Duke Cancer Institute Flow Cytometry Shared Resource using a BD FACSCanto II flow cytometer. Data was analyzed using FlowJo v10.1 software (FlowJo, LLC). For analysis only single cells were used (gated using the FSC/SSC plot). For chitin exposure analysis cells were gated in the CFW intensity/ Alexa488-WGA intensity scatter plot. 
Cells sizes were measured using the ImageJ measurement tool. Capsule thickness was calculated using

Additional histograms with mean fluorescence intensity (MFI) on the $x$-axis and cell counts on the $y$-axis were created. Unstained cells were used as negative controls.

buffer (0.2 M Na2HPO4, $0.1 \mathrm{M}$ citric acid, pH 6.0). Then, cells were stained using $500 \mu \mathrm{L}$ of $300 \mu \mathrm{g} / \mathrm{ml}$ Eosin $\mathrm{Y}$ in Mcllvaine's buffer for 10 minutes at room temperature in the dark. Cells were then washed $2 \mathrm{x}$ with Mcllvaine's buffer and resuspended in 20-50 $\mu \mathrm{L}$ Mcllvaine's buffer. Cells were visualized using a GFP filter.

\section{Microscopic quantification}

Differential interference microscopy (DIC) and fluorescent images were visualized with a Zeiss Axio Imager fluorescence microscope (64X objectives). Images were taken with an AxioCam MRm digital camera with ZEN Pro software (Zeiss). The same exposure time was used to image all strains analyzed. Images were analyzed using ImageJ/Fiji software. Gray scale values were measured and normalized towards cell count. The intensity of the control strain (=Cu sufficient WT) was set to 1 . Results are reported as relative fluorescence intensity $+/$ - standard error of the means.

the equation:

capsule thickness $=\frac{\text { (cell diameter including capsule }- \text { cell body diamter })}{2}$

\section{Generation of bone marrow derived macrophages}

Murine bone marrow cells were isolated from A/J mice and prepared as previously described [31]. 
7.4) and cells were resuspended in 1x Dulbecco's modified Eagle's medium (DMEM; + 4.5 g/L D-Glucose, cryopreserved in $90 \% \mathrm{FBS} / 10 \%$ endotoxin-free DMSO at a concentration of $1 \times 10^{7}$ cells $/ \mathrm{ml}$.

BMMs were differentiated in BMM medium (1x Dulbecco's modified Eagle's medium [DMEM; + 4.5 inactivated], $1 \mathrm{U} / \mathrm{ml}$ penicillin/streptomycin) with $3 \mathrm{ng} / \mathrm{ml}$ recombinant mouse GM-CSF (rGM-CSF; R\&D confluency was achieved. The Duke University Institutional Animal Care and Use Committee reviewed and approved the protocol for the macrophage harvesting. Protocol registry number A102-20-05.

\section{Macrophage co-incubation and TNF- $\alpha$ quantification}

Prior to co-incubation, overnight cultures of $\mathrm{C}$. neoformans strains $\left(\mathrm{YPD}, 30^{\circ} \mathrm{C}\right.$ ) were harvested and co-incubation assay, BMMs were counted (by hemocytometer, with Trypan blue to discount dead cells), plated in BMM medium in 96-well plates at a concentration of $5 \times 10^{4}$ cells/well and incubated at $37^{\circ} \mathrm{C}$

666 (10:1 C. neoformans cells:BMMs). Co-cultures were incubated for $6 \mathrm{~h}$ at $37^{\circ} \mathrm{C}$ with $5 \% \mathrm{CO}_{2}$. Supernatants 


\section{Statistical analysis}

671 For all data error bars represent statistical errors of the means (SEM) of results from a number of biological

672 replicates $(\mathrm{N})$, as indicated in figure legends. Before statistical analysis was conducted, data from all

673 experiments was log transformed for comparison of proportions. Statistical analysis was performed with

674 GraphPad Prism software v9. The statistical tests chosen for each experiment and their results (i.e., $p$

675 values) are indicated in figure legends. Asterisks in figures correspond to statistical significance as follows:

$676 * * * *, \mathrm{P}<0.0001 ; * * *, \mathrm{P}=0.0001$ to $\mathrm{P}<0.001 ; * *, \mathrm{P}=0.001$ to $\mathrm{P}<0.01 ; *, \mathrm{P}=0.01$ to $\mathrm{P}<0.05 ;$ ns (not

677 significant), $\mathrm{P}>0.05$.

678

679 Acknowledgements

We thank the Duke Cancer Institute for the use of the Flow Cytometry Shared Resource. The Transmission

electron microscopy was performed in part at the Duke University Shared Materials Instrumentation

682 Facility (SMIF), a member of the North Carolina Research Triangle Nanotechnology Network (RTNN),

which is supported by the National Science Foundation (award number ECCS-2025064) as part of the

689 Ralle for her help and insight in sample preparation and ICP-MS data acquisition and Dr. Aaron D. Smith 


\section{$\underline{\text { References }}$}

695 1. Bleackley MR, MacGillivray RTA. Transition metal homeostasis: from yeast to human disease.

696 BioMetals. 2011;24(5):785-809. doi: 10.1007/s10534-011-9451-4.

697 2. Smith AD, Logeman BL, Thiele DJ. Copper Acquisition and Utilization in Fungi. Annu Rev Microbiol. 2017;71:597-623. Epub 2017/09/10. doi: 10.1146/annurev-micro-030117-020444. PubMed PMID:

3. Hood MI, Skaar EP. Nutritional immunity: transition metals at the pathogen-host interface. Nat

701 Rev Microbiol. 2012;10(8):525-37. Epub 2012/07/17. doi: 10.1038/nrmicro2836. PubMed PMID:

4. Garcia-Santamarina S, Festa RA, Smith AD, Yu CH, Probst C, Ding C, et al. Genome-wide analysis Epub 2018/04/03. doi: 10.1111/mmi.13960. PubMed PMID: 29608794; PubMed Central PMCID:

707 5. Garcia-Santamarina S, Probst C, Festa RA, Ding C, Smith AD, Conklin SE, et al. A lytic polysaccharide monooxygenase-like protein functions in fungal copper import and meningitis. Nature Chemical Biology. 2020;16(3):337-44. doi: 10.1038/s41589-019-0437-9.

710 6. Brander S, Horvath I, Ipsen JO, Peciulyte A, Olsson L, Hernandez-Rollan C, et al. Biochemical 711 evidence of both copper chelation and oxygenase activity at the histidine brace. Sci Rep. 712 2020;10(1):16369. Epub 2020/10/03. doi: 10.1038/s41598-020-73266-y. PubMed PMID: 33004835;

713 PubMed Central PMCID: PMCPMC7529816.

714 7. Labourel A, Frandsen $\mathrm{KEH}$, Zhang F, Brouilly N, Grisel S, Haon M, et al. A fungal family of Iytic 715 polysaccharide monooxygenase-like copper proteins. Nature Chemical Biology. 2020;16(3):345-50. doi: 
717 8. Garcia-Rubio R, de Oliveira HC, Rivera J, Trevijano-Contador N. The Fungal Cell Wall: Candida,

718 Cryptococcus, and Aspergillus Species. Front Microbiol. 2019;10:2993. Epub 2020/01/30. doi:

719 10.3389/fmicb.2019.02993. PubMed PMID: 31993032; PubMed Central PMCID: PMCPMC6962315.

720 9. Hopke A, Brown AJP, Hall RA, Wheeler RT. Dynamic Fungal Cell Wall Architecture in Stress

721 Adaptation and Immune Evasion. Trends Microbiol. 2018;26(4):284-95. Epub 2018/02/18. doi:

722 10.1016/j.tim.2018.01.007. PubMed PMID: 29452950; PubMed Central PMCID: PMCPMC5869159.

723 10. Camacho E, Vij R, Chrissian C, Prados-Rosales R, Gil D, O'Meally RN, et al. The structural unit of

724 melanin in the cell wall of the fungal pathogen Cryptococcus neoformans. Journal of Biological Chemistry.

725 2019;294(27):10471-89. doi: https://doi.org/10.1074/jbc.RA119.008684.

726 11. O'Meara TR, Alspaugh JA. The Cryptococcus neoformans Capsule: a Sword and a Shield.

727 2012;25(3):387-408. doi: doi:10.1128/CMR.00001-12.

728 12. Erwig LP, Gow NAR. Interactions of fungal pathogens with phagocytes. Nature Reviews 729 Microbiology. 2016;14(3):163-76. doi: 10.1038/nrmicro.2015.21.

730 13. Ost KS, Esher SK, Leopold Wager CM, Walker L, Wagener J, Munro C, et al. Rim Pathway-Mediated

731 Alterations in the Fungal Cell Wall Influence Immune Recognition and Inflammation. mBio. 2017;8(1).

732 Epub 2017/02/02. doi: 10.1128/mBio.02290-16. PubMed PMID: 28143983; PubMed Central PMCID: PMCPMC5285508.

734 14. Mahl CRA, Taketa TB, Rocha-Neto JBM, Almeida WP, Beppu MM. Copper Ion Uptake by Chitosan 735 in the Presence of Amyloid-beta and Histidine. Appl Biochem Biotechnol. 2020;190(3):949-65. Epub 736 2019/10/21. doi: 10.1007/s12010-019-03120-z. PubMed PMID: 31630339.

737 15. M.D. Mullen DCW, T.J. Beveridge, G.W. Bailey,. Sorption of heavy metals by the soil fungi 738 Aspergillus niger and Mucor rouxii,. Soil Biology and Biochemistry. 1992; 24(2):129-35. doi: https://doi.org/10.1016/0038-0717(92)90268-3. 
16. Staudt MW, Kruzel EK, Shimizu K, Hull CM. Characterizing the role of the microtubule binding protein Bim1 in Cryptococcus neoformans. Fungal genetics and biology : FG \& B. 2010;47(4):310-7. Epub 2010/01/02. doi: 10.1016/j.fgb.2009.12.010. PubMed PMID: 20044015; PubMed Central PMCID: PMCPMC2835843.

744 17. Dichtl K, Samantaray S, Wagener J. Cell wall integrity signalling in human pathogenic fungi. Cell 745 Microbiol. 2016;18(9):1228-38. Epub 2016/05/08. doi: 10.1111/cmi.12612. PubMed PMID: 27155139.

747 Pathway Involved in Morphogenesis, Virulence and Antifungal Susceptibility in Cryptococcus neoformans. Journal of fungi (Basel, Switzerland). 2021;7(10). Epub 2021/10/24. doi: 10.3390/jof7100831. PubMed PMID: 34682253; PubMed Central PMCID: PMCPMC8540506. 2958.2006.05300.x. PubMed PMID: 16925551.

754 20. Heilmann CJ, Sorgo AG, Mohammadi S, Sosinska GJ, de Koster CG, Brul S, et al. Surface stress 755 induces a conserved cell wall stress response in the pathogenic fungus Candida albicans. Eukaryot Cell. 2013;12(2):254-64. Epub 2012/12/18. doi: 10.1128/EC.00278-12. PubMed PMID: 23243062.

757 21. Baker LG, Specht CA, Donlin MJ, Lodge JK. Chitosan, the deacetylated form of chitin, is necessary 758 for cell wall integrity in Cryptococcus neoformans. Eukaryot Cell. 2007;6(5):855-67. Epub 2007/04/03. doi: 759 10.1128/EC.00399-06. PubMed PMID: 17400891; PubMed Central PMCID: PMCPMC1899242.

760 22. Sun T-S, Ju X, Gao H-L, Wang T, Thiele DJ, Li J-Y, et al. Reciprocal functions of Cryptococcus 761 neoformans copper homeostasis machinery during pulmonary infection and meningoencephalitis. Nature 762 Communications. 2014;5(1):5550. doi: 10.1038/ncomms6550. 

pathogen Cryptococcus neoformans. Mol Microbiol. 2005;57(5):1381-96. Epub 2005/08/17. doi: 10.1111/j.1365-2958.2005.04779.x. PubMed PMID: 16102007.

24. Saikia S, Oliveira D, Hu G, Kronstad J, Deepe GS. Role of Ferric Reductases in Iron Acquisition and

767 Virulence in the Fungal Pathogen Cryptococcus neoformans. 2014;82(2):839-50. doi: doi:10.1128/IAI.01357-13.

25. Jung WH, Kronstad JW. Iron and fungal pathogenesis: a case study with Cryptococcus neoformans.

Cell Microbiol. 2008;10(2):277-84. Epub 2007/11/29. doi: 10.1111/j.1462-5822.2007.01077.x. PubMed PMID: 18042257.

772 26. Kronstad JW, Hu G, Jung WH. An encapsulation of iron homeostasis and virulence in Cryptococcus 773 neoformans. Trends Microbiol. 2013;21(9):457-65. Epub 2013/07/03. doi: 10.1016/j.tim.2013.05.007. 774 PubMed PMID: 23810126; PubMed Central PMCID: PMCPMC3769505.

775 27. Mukaremera L, Lee KK, Wagener J, Wiesner DL, Gow NAR, Nielsen K. Titan cell production in 776 Cryptococcus neoformans reshapes the cell wall and capsule composition during infection. The Cell 777 Surface. 2018;1:15-24. doi: https://doi.org/10.1016/j.tcsw.2017.12.001.

778 28. Dambuza IM, Drake T, Chapuis A, Zhou X, Correia J, Taylor-Smith L, et al. The Cryptococcus 779 neoformans Titan cell is an inducible and regulated morphotype underlying pathogenesis. PLoS Pathog. 780 2018;14(5):e1006978. Epub 2018/05/19. doi: 10.1371/journal.ppat.1006978. PubMed PMID: 29775474; 781 PubMed Central PMCID: PMCPMC5959070.

782 29. Chrissian C, Camacho E, Fu MS, Prados-Rosales R, Chatterjee S, Cordero RJB, et al. Melanin 783 deposition in two Cryptococcus species depends on cell-wall composition and flexibility. J Biol Chem. 784 2020;295(7):1815-28. Epub 2020/01/04. doi: 10.1074/jbc.RA119.011949. PubMed PMID: 31896575; 
30. Ding C, Yin J, Tovar EM, Fitzpatrick DA, Higgins DG, Thiele DJ. The copper regulon of the human

787

788

fungal pathogen Cryptococcus neoformans H99. Mol Microbiol. 2011;81(6):1560-76. Epub 2011/08/09. doi: 10.1111/j.1365-2958.2011.07794.x. PubMed PMID: 21819456; PubMed Central PMCID: PMCPMC3718005.

31. Ost KS, O'Meara TR, Huda N, Esher SK, Alspaugh JA. The Cryptococcus neoformans alkaline response pathway: identification of a novel rim pathway activator. PLoS Genet. 2015;11(4):e1005159. Epub 2015/04/11. doi: 10.1371/journal.pgen.1005159. PubMed PMID: 25859664; PubMed Central PMCID: PMCPMC4393102.

32. Esher SK, Ost KS, Kohlbrenner MA, Pianalto KM, Telzrow CL, Campuzano A, et al. Defects in intracellular trafficking of fungal cell wall synthases lead to aberrant host immune recognition. PLOS Pathogens. 2018;14(6):e1007126. doi: 10.1371/journal.ppat.1007126.

33. Pianalto KM, Billmyre RB, Telzrow CL, Alspaugh JA. Roles for Stress Response and Cell Wall Biosynthesis Pathways in Caspofungin Tolerance in Cryptococcus neoformans. Genetics. 2019;213(1):21327. Epub 2019/07/04. doi: 10.1534/genetics.119.302290. PubMed PMID: 31266771; PubMed Central PMCID: PMCPMC6727808.

34. Walker LA, Munro CA, de Bruijn I, Lenardon MD, McKinnon A, Gow NAR. Stimulation of Chitin Synthesis Rescues Candida albicans from Echinocandins. PLOS Pathogens. 2008;4(4):e1000040. doi: 10.1371/journal.ppat.1000040.

35. Fortwendel JR, Juvvadi PR, Perfect BZ, Rogg LE, Perfect JR, Steinbach WJ. Transcriptional regulation of chitin synthases by calcineurin controls paradoxical growth of Aspergillus fumigatus in response to caspofungin. Antimicrobial agents and chemotherapy. 2010;54(4):1555-63. Epub 2010/02/04. doi: 10.1128/aac.00854-09. PubMed PMID: 20124000; PubMed Central PMCID: PMCPMC2849361. 
36. Frases S, Pontes B, Nimrichter L, Viana NB, Rodrigues ML, Casadevall A. Capsule of

$810<$ em>Cryptococcus neoformans $</$ em $>$ grows by enlargement of polysaccharide molecules.

811 2009;106(4):1228-33. doi: 10.1073/pnas.0808995106 \%J Proceedings of the National Academy of

812 Sciences.

813 37. Jiang N, Sun N, Xiao D, Pan J, Wang Y, Zhu X. A copper-responsive factor gene CUF1 is required for 814 copper induction of laccase in Cryptococcus neoformans. FEMS microbiology letters. 2009;296(1):84-90.

815 Epub 2009/05/23. doi: 10.1111/j.1574-6968.2009.01619.x. PubMed PMID: 19459959.

816 38. Ding C, Festa RA, Chen YL, Espart A, Palacios Ò, Espín J, et al. Cryptococcus neoformans copper 817 detoxification machinery is critical for fungal virulence. Cell host \& microbe. 2013;13(3):265-76. Epub 818 2013/03/19. doi: 10.1016/j.chom.2013.02.002. PubMed PMID: 23498952; PubMed Central PMCID: 819 PMCPMC3668348.

820 39. Li C, Li Y, Ding C. The Role of Copper Homeostasis at the Host-Pathogen Axis: From Bacteria to 821 Fungi. Int J Mol Sci. 2019;20(1):175. doi: 10.3390/ijms20010175. PubMed PMID: 30621285.

822 40. Garcia-Santamarina S, Uzarska MA, Festa RA, Lill R, Thiele DJ. Cryptococcus neoformans Iron823 Sulfur Protein Biogenesis Machinery Is a Novel Layer of Protection against Cu Stress. mBio [Internet]. 2017 $8242017 / 10 / / ; 8(5)$

825 41. Sun T, Li Y, Li Y, Li H, Gong Y, Wu J, et al. Proteomic Analysis of Copper Toxicity in Human Fungal 826 Pathogen Cryptococcus neoformans. 2021;11(747). doi: 10.3389/fcimb.2021.662404.

827 42. Sun T, Li X, Song W, Yu S, Wang L, Ding C, et al. Metabolomic alterations associated with copper 828 stress in Cryptococcus neoformans. Future Microbiol. 2021;16:305-16. Epub 2021/02/27. doi: 829 10.2217/fmb-2020-0290. PubMed PMID: 33635120.

830 43. Broxton CN, Culotta VC. An Adaptation to Low Copper in Candida albicans Involving SOD Enzymes 831 and the Alternative Oxidase. PLOS ONE. 2016;11(12):e0168400. doi: 10.1371/journal.pone.0168400. 
44. Kropat J, Gallaher SD, Urzica El, Nakamoto SS, Strenkert D, Tottey S, et al. Copper economy in

833 Chlamydomonas: prioritized allocation and reallocation of copper to respiration vs. photosynthesis. Proc

834 Natl Acad Sci U S A. 2015;112(9):2644-51. Epub 2015/02/04. doi: 10.1073/pnas.1422492112. PubMed

PMID: 25646490; PubMed Central PMCID: PMCPMC4352834.

836 45. Smith AD, Garcia-Santamarina S, Ralle M, Loiselle DR, Haystead TA, Thiele DJ. Transcription factor-

837 driven alternative localization of Cryptococcus neoformans superoxide dismutase. J Biol Chem.

838 2021;296:100391. Epub 2021/02/11. doi: 10.1016/j.jbc.2021.100391. PubMed PMID: 33567338; PubMed

839 Central PMCID: PMCPMC7961099.

840 46. Ipsen $\rfloor \emptyset$, Hallas-Møller M, Brander S, Lo Leggio L, Johansen KS. Lytic polysaccharide

841 monooxygenases and other histidine-brace copper proteins: structure, oxygen activation and

842 biotechnological applications. Biochemical Society Transactions. 2021;49(1):531-40. doi:

843 10.1042/BST20201031 \%J Biochemical Society Transactions.

844 47. Rani Singhania R, Dixit P, Kumar Patel A, Shekher Giri B, Kuo C-H, Chen C-W, et al. Role and 845 significance of lytic polysaccharide monooxygenases (LPMOs) in lignocellulose deconstruction. 846 Bioresource Technology. 2021;335:125261. doi: https://doi.org/10.1016/j.biortech.2021.125261.

847 48. Black B, Lee C, Horianopoulos LC, Jung WH, Kronstad JW. Respiring to infect: Emerging links 848 between mitochondria, the electron transport chain, and fungal pathogenesis. PLoS pathogens. 849 2021;17(7):e1009661-e. doi: 10.1371/journal.ppat.1009661. PubMed PMID: 34237096.

850 49. Hole CR, Lam WC, Upadhya R, Lodge JK. Cryptococcus neoformans Chitin Synthase 3 Plays a 851 Critical Role in Dampening Host Inflammatory Responses. mBio. 2020;11(1). Epub 2020/02/20. doi:

852 10.1128/mBio.03373-19. PubMed PMID: 32071275; PubMed Central PMCID: PMCPMC7029146.

853 50. Hembach L, Bonin M, Gorzelanny C, Moerschbacher BM. Unique subsite specificity and potential 854 natural function of a chitosan deacetylase from the human pathogen Cryptococcus neoformans. Proc Natl 
Acad Sci U S A. 2020;117(7):3551-9. Epub 2020/02/06. doi: 10.1073/pnas.1915798117. PubMed PMID:

857 51. Fonseca FL, Guimarães AJ, Kmetzsch L, Dutra FF, Silva FD, Taborda CP, et al. Binding of the wheat germ lectin to Cryptococcus neoformans chitooligomers affects multiple mechanisms required for fungal pathogenesis. Fungal genetics and biology : FG \& B. 2013;60:64-73. Epub 2013/04/24. doi: 10.1016/j.fgb.2013.04.005. PubMed PMID: 23608320; PubMed Central PMCID: PMCPMC4294701. neoformans by use of biolistic delivery of DNA. Journal of bacteriology. 1993;175(5):1405-11. Epub 1993/03/01. doi: 10.1128/jb.175.5.1405-1411.1993. PubMed PMID: 8444802; PubMed Central PMCID: PMCPMC193227.

\section{Figure Legends}

Figure 1: The Cuf1 transcription factor as well as it targets Cbi1 and Ctr1 are involved in maintaining cell wall integrity during copper deficiency.

869 (A) qRT-PCR analysis of the ROM2 transcript level in indicated strains. For the high copper condition, the WT, cuf1 $\Delta$ and Cuf1-Flag complemented cuf1 $\Delta^{C}$ strains were inoculated to $\mathrm{OD}_{600} 0.3$ in SC supplemented

871 with $1 \mathrm{mM} \mathrm{CuSO}_{4}$ and cultivated for $1 \mathrm{~h}$ at $30^{\circ} \mathrm{C}$. To induce low copper conditions, indicated strains were

872 inoculated to $\mathrm{OD}_{600} 0.3$ in SC supplemented with $1 \mathrm{mM} \mathrm{BCS}$ and cultivated for $6 \mathrm{~h}$ at $30^{\circ} \mathrm{C}$. For comparison

873 the WT ROM2 transcript levels at each condition were set to 1. Presented is the mean +/- SEM of the 874 relative transcript levels of 4 biological replicates. A 2-way ANOVA was performed using GraphPad Prism 875 from log transformed data. (B) Growth analysis in presence of cell wall/ surface stressors. The spotting assay was performed on SC supplemented with $100 \mu \mathrm{M}$ BCS which was co-supplemented with indicated 
were diluted to $\mathrm{OD}_{600} 0.25$ and a serial 1:10 dilution was spotted onto media plates. Plates were incubated at $30^{\circ} \mathrm{C}$ for $2-4 \mathrm{~d}$. This figure shows a representative image from 3 independent spotting experiments. (C) GAL7 promoter-driven expression of Cbi1 in different cuf1 $\Delta$ ctr $\Delta$ strains during cell wall stress. The spotting assay was performed on SC with either glucose (SC-Glu) or galactose (SC-Gal) as carbohydrate source, supplemented with indicated amounts of $\mathrm{CuSO}_{4}, \mathrm{BCS}$ and congo red. Indicated strains were grown overnight in $\mathrm{SC}$ at $30^{\circ} \mathrm{C}$. Cells were diluted in $\mathrm{PBS}$ to $\mathrm{OD}_{600} 0.25$, and a serial 1:10 dilution was spotted on to media plates. Plates were incubated at $30^{\circ} \mathrm{C}$ for $3 \mathrm{~d}$. This figure shows a representative image from 3 independent spotting experiments. (D) Growth of WT, cbi1 $\Delta$ and Cbi1 WT complemented $c b i 1 \Delta\left(c b i 1 \Delta^{C-W T}\right)$ in presence of $0.01 \%$ SDS in YPEG w/o $5 \mu \mathrm{M} \mathrm{CuSO}_{4}$. Growth was measured via $\mathrm{OD}_{600}$ after $72 \mathrm{~h}$ at $30^{\circ} \mathrm{C}$ and was normalized to WT growth in YPEG media. Presented is the mean +/- SEM of the relative growth rates of 3 biological replicates. 1-way ANOVA was performed using GraphPad Prism from log transformed data. assay was performed on SC supplemented with $100 \mu \mathrm{M}$ or $500 \mu \mathrm{M}$ BCS which was co-supplemented with and a serial 1:10 dilution was spotted on to media plates. Plates were incubated at $30^{\circ} \mathrm{C}$ for $2-4 \mathrm{~d}$. (D) Copper restoration of cell wall stressor sensitivity of $c b i 1 \Delta$ cells. The spotting assay was performed on SC+ grown overnight in $\mathrm{SC}$ at $30^{\circ} \mathrm{C}$. Cells were diluted to $\mathrm{OD}_{600}$ of 2.5 and a serial 1:10 dilution was spotted on to media plates. Plates were incubated at $30^{\circ} \mathrm{C}$ for $3 \mathrm{~d}$. This figure shows a representative image from 3

897 independent spotting experiments. 
901 TEM images of copper sufficient or deficient WT and cbi1s cells. Cells were incubated in YPD

902 supplemented with $10 \mu \mathrm{M} \mathrm{CuSO}_{4}$ (Cu sufficiency) or with $250 \mu \mathrm{M} \mathrm{BCS}$ (Cu deficiency) for $24 \mathrm{~h}$ at $30^{\circ} \mathrm{C}$. (A)

903 Representative images of the TEM analysis (in $29000 \times$ magnification). (B) Quantification of cell wall

904 thickness. Measurements were performed using the ImageJ/Fiji measurement tool: Cu sufficiency-WT 10

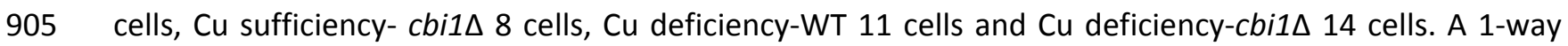

906 ANOVA was performed using GraphPad Prism from log transformed data. (C) Quantification of the cell

907 wall staining intensity. Presented is the analysis of two sets of TEM images. The gray value was measured

908 with ImageJ/Fiji and plotted against the distance along the cell wall. (D) qRT-PCR analysis Transcripts

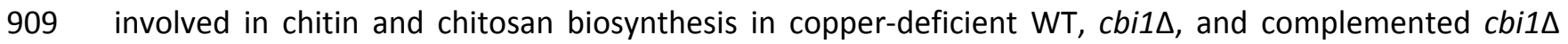

$910\left(c b i 1 \Delta^{C-W T}\right)$ cells. Cells were inoculated to $\mathrm{OD}_{600} 0.05$ in YPD supplemented with $250 \mu \mathrm{M}$ BCS and cultivated

911 for $24 \mathrm{~h}$ at $30^{\circ} \mathrm{C}$. For comparison, the WT transcript levels were set to 1 . Presented is the mean $+/-\mathrm{SEM}$ of

912 the relative transcript levels of minimum 4 biological replicates. A 1-way ANOVA was performed using

913 GraphPad Prism from log transformed data. (E) qRT-PCR analysis Transcripts involved in glucan

914 biosynthesis in copper deficiency. Cells were treated as described in (A). Presented is the mean +/- SEM

915 of the relative transcript levels of minimum 4 biological replicates. A 1-way ANOVA was performed using

916 GraphPad Prism from log transformed data.

Figure 3: Cbi1 affects cell wall chitin and chitosan deposition and architecture during copper deficiency.

919 (A)-(B) MBTH based chitin/chitosan quantification from purified cell wall material of copper sufficient (A)

920 or deficient (B) WT, cbi1 $\Delta$ and Cbi1 WT complemented cbi1 $\left(c b i 1 \Delta^{c-W T}\right)$ cells. Strains were incubated for

$92124 \mathrm{~h}$ in YPD+ 10 uM CuSO4 (copper sufficiency) or YPD +250 uM BCS (copper deficiency). Values are shown

922 in uM Glucosamin $/ 10^{7}$ cells. Presented is the mean +/- SEM of 3 biological replicates. A 1-way ANOVA was

923 performed using GraphPad Prism from log transformed data. (C) Calcofluor white (CFW) and wheat germ 
agglutin (WGA)-Alexa 488 staining for chitin of copper sufficient or deficient WT, cbi1 $\Delta$ and and Cbi1 WT

complemented cbi1 $\Delta\left(c_{b i 1}{ }^{c-W T}\right)$ cells. Strains were as described in (A) and double stained with CFW and

WGA-Alexa 488. Shown are representative images. Three independent treatments and stainings were performed. (D) EosinY staining for chitosan of copper sufficient and deficient WT, cbi1 $\Delta$ and Cbi1 WT complemented cbi1 $\left(c b i 1 \Delta^{c-W T}\right)$ cells. Strains were cultivated as described in $(A)$, followed by EosinY staining. Shown are representative images. Five independent treatments and staining were performed.

profiles of indicated copper sufficient or deficient strains, (F) and (H) show the quantification of the

935 population pattern from 3 independent experiments. A 2-way ANOVA was performed using GraphPad Prism from log transformed data.

939 (A) Proposed model for the role of chitosan deposition to withstand copper stress. The cryptococcal cell wall is a dynamic multi-layered compartment build up by the sugar polymers chitin, $\alpha$ - and $\beta$-glucans.

941 Chitin (solid blue) and its deacetylated form chitosan (dotted blue) build the inner cell wall layer, which is 942 covered by an upper layer of $\beta$-glucans (purple) and $\alpha$-glucans (black). The pigment melanin (brown 943 circles) is incorporated and attached to cell wall chitosan, and the cryptococcal capsule (green dots) is 944 attached to $\alpha$-glucans. (B-C) Growth analysis in the presence of low (B) and high (C) copper stress. The 945 spotting assay was performed on YPD supplemented with indicated amounts of $\mathrm{BCS}$ or $\mathrm{CuSO}_{4}$. Indicated 
strains were grown overnight in $\mathrm{YPD}$ at $30^{\circ} \mathrm{C}$. Cells were diluted to $\mathrm{OD}_{600}$ of 0.2 and a serial 1:10 dilution was spotted on to media plates. Plates were incubated at $30^{\circ} \mathrm{C}$ for $2-6 \mathrm{~d}$.

(A) Macrophage activation assay upon infection with copper sufficient or deficient WT, cbi1 $\Delta$ and $c b i 1 \Delta^{c-}$

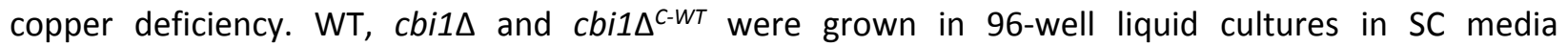
supplemented with $100 \mu \mathrm{M}$ BCS and were co-treated with 0 to $100 \mathrm{ug} / \mathrm{mL}$ caspofungin. $\mathrm{OD}_{600}$ was measured after $24 \mathrm{~h}$ of growth at $30^{\circ} \mathrm{C}$ and the $\mathrm{OD}_{600}$ of the non-treated condition was set to 1 . Presented is the mean +/-SEM of 4 independent experiments. A 2-way ANOVA was performed using GraphPad Prism from log transformed data. (C) Melanization of $\mathrm{WT}, \mathrm{cbi1 \Delta}, \mathrm{ctr} 1 \Delta$ and $\operatorname{ctr} 4 \Delta$ cells in the absence and presence of $5 \mathrm{MMCuSO}_{4}$. Overnight cultures were harvested, washed $1 \mathrm{x}$ with PBS, diluted to $\mathrm{OD}_{600} 2.5$ and spotted on to L-DOPA plates. Shown are representative images from 3 independent experiments. (D) Analysis of capsule formation using India ink contrast staining of WT, cbi1 $\Delta$ and $c b i 1 \Delta^{c-W T}$ complemented cells. Indicated strains were grown for $3 d$ in capsule inducing conditions in presence and absence of 250 $\mu \mathrm{M}$ BCS. Cell were harvest, resuspended in PBS, stained with India ink (1:1) and analyzed using the DIC channel. Shown are representative images from 3 independent experiments. (E) Quantification of capsule size from India ink staining. Images taken were analyzed with imageJ/Fiji. A minimum of 170 cells of each

967 strain were analyzed. Data are presented as box and whiskers diagram with indicated median and min 
the log transformed data. (F) Scanning electron microscopy (SEM) analysis of WT and cbi1 $\Delta$ cells in absence and presence of $250 \mu \mathrm{M}$ BCS.

Supp Fig. 1:

973 (A) Growth analysis in presence of cell wall/ surface stressors. The spotting assay was performed on SC

974 supplemented with indicated amounts of cell wall and cell surface stressors. Indicated strains were grown overnight in $\mathrm{SC}$ at $30^{\circ} \mathrm{C}$. Cells were diluted to $\mathrm{OD}_{600}$ of 0.25 and a serial $1: 10$ dilution was spotted on to media plates. Plates were incubated at $30^{\circ} \mathrm{C}$ for $2-4 \mathrm{~d}$. This figure shows a representative image from 3

977 independent spotting experiments. (B) Growth rate of copper sufficient or deficient WT and cbi1 $\Delta$ cells.

978 Cells were incubated in YPD supplemented with $10 \mu \mathrm{M} \mathrm{CuSO}_{4}$ (Cu sufficiency) or with $250 \mu \mathrm{M} \mathrm{BCS}$ (Cu

979 deficiency) for $24 \mathrm{~h}$ at $30^{\circ} \mathrm{C}$. Growth was measured through $0 \mathrm{D}_{600}$. Presented is the average $+/-\mathrm{SEM}$ of 5

980 biological replicates. (C) Colony forming unit (CFU) analysis of copper sufficient or deficient WT and cbi1

981 cells. Cells were treated as described in (B). After $24 \mathrm{~h}$ of growth, cells were diluted to $\mathrm{OD}_{600} 1.200 \mu \mathrm{L}$ of a

982 serial 1:1000 dilution were plated onto YPD plates and colonies were counted after $3 \mathrm{~d}$ of incubation at

$98330^{\circ} \mathrm{C}$. The CFU of copper sufficient WT was set to $100 \%$. Presented is the average +/- SEM of the relative

984 CFU (as compared to copper sufficient WT) from 4 biological replicates. (D) qRT-PCR analysis using CMT1

985 and CTR4 as indicator for Cu toxicity or deficiency. Indicated cells were cultivated as described in (B) and

986 used for RNA extraction, followed by cDNA synthesis. Presented is $\Delta \Delta C_{T}$ of copper deficiency: copper

987 sufficiency. The average +/- SEM from 3 biological replicates is shown. (E-F) ICP-MS based metal 988 quantification of cell associated copper $(\mathrm{E})$ and Iron $(\mathrm{F})$ in pg metal per $10^{6}$ cells. Indicated strains were 989 grown as described in (B). Presented is the average +/- SEM from 3 biological replicates. 
992 (A) $\beta$-glucan quantification of copper sufficient and copper deficient wt, cbi1 $\Delta$ and $c b i 1 \Delta^{c-W T}$ 993 complemented cells. Strains were incubated for 24h in YPD+ 10 uM CuSO4 (Cu sufficiency) or YPD +250 994 UM BCS (Cu deficiency) and then harvested, cell counted and lyophilized. The Megazyme yeast b-glucan 995 kit was used for quantification of b-glucan from lyophilized cells. Values are shown in ug Glucose / $10^{7}$ 996 cells. Presented is the average +/- SEM of 3 biological replicates. (B) Calcofluor white (CFW) and wheat 997 germ agglutin (WGA)-Alexa 488 staining for chitin of copper sufficient or deficient WT, cbi1 $\Delta$ and and Cbi1 998 WT complemented $c b i 1 \Delta\left(c b i 1 \Delta^{c-W T}\right)$ cells. Strains were cultivated as described in $(\mathrm{A})$. Shown is the mean 999 +/- SEM of the relative CFW intensity from 3 independent experiments. The CFW intensities were 1000 measured with ImageJ/Fiji and normalized to cell count. Shown is the relative CFW intensity (copper 1001 sufficient WT set to 1). A 1-way ANOVA was performed using GraphPad Prism from log transformed data.

1002 (C) EosinY staining for chitosan of copper sufficient and deficient WT, cbi1 $\Delta$ and $c b i 1 \Delta^{c-W T}$ complemented 1003 cells. Strains were cultivated as described in (A), followed by EosinY staining. Shown are representative 1004 images for 2 two independent experiments. Five independent treatments and stainings were performed. 1005 (D) Relative EosinY intensity from 5 independent experiments. The EosinY intensities were measure with 1006 ImageJ/Fiji and normalized to cell count. Shown is mean +/- SEM of the relative EosinY intensity (copper 1007 sufficient WT set to 1). A 1-way ANOVA was performed using GraphPad Prism from log transformed data. 1008 (E-F) FACS analysis of CFW and WGA-Alexa 488 stained cells. WT, cbi1 $\Delta$ and $c b i 1 \Delta^{c-W T}$ complemented cells 1009 were cultivated as described in (A) (E) WGA-Alexa 488 staining histogram representation of the FACS 1010 analysis depicted in Fig 3. (F) CFW-staining histogram representation of FACS analysis depicted in Fig3. (G) 1011 Minimal inhibitory concentration (MIC) analysis of Caspofungin during copper sufficiency. WT, cbi1 $\Delta$ and $1012 \quad c b i 1 \Delta^{C-W T}$ complemented cells were grown in 96-well liquid cultures in SC media supplemented with 0 to $1013100 \mathrm{ug} / \mathrm{mL}$ Caspofungin. $\mathrm{OD}_{600}$ were measured after $24 \mathrm{~h}$ growth at $30^{\circ} \mathrm{C}$ and the $\mathrm{OD}_{600}$ of the non-treated 1014 condition was set to 1 . Presented is the mean +/- SEM of 4 independent experiments. 

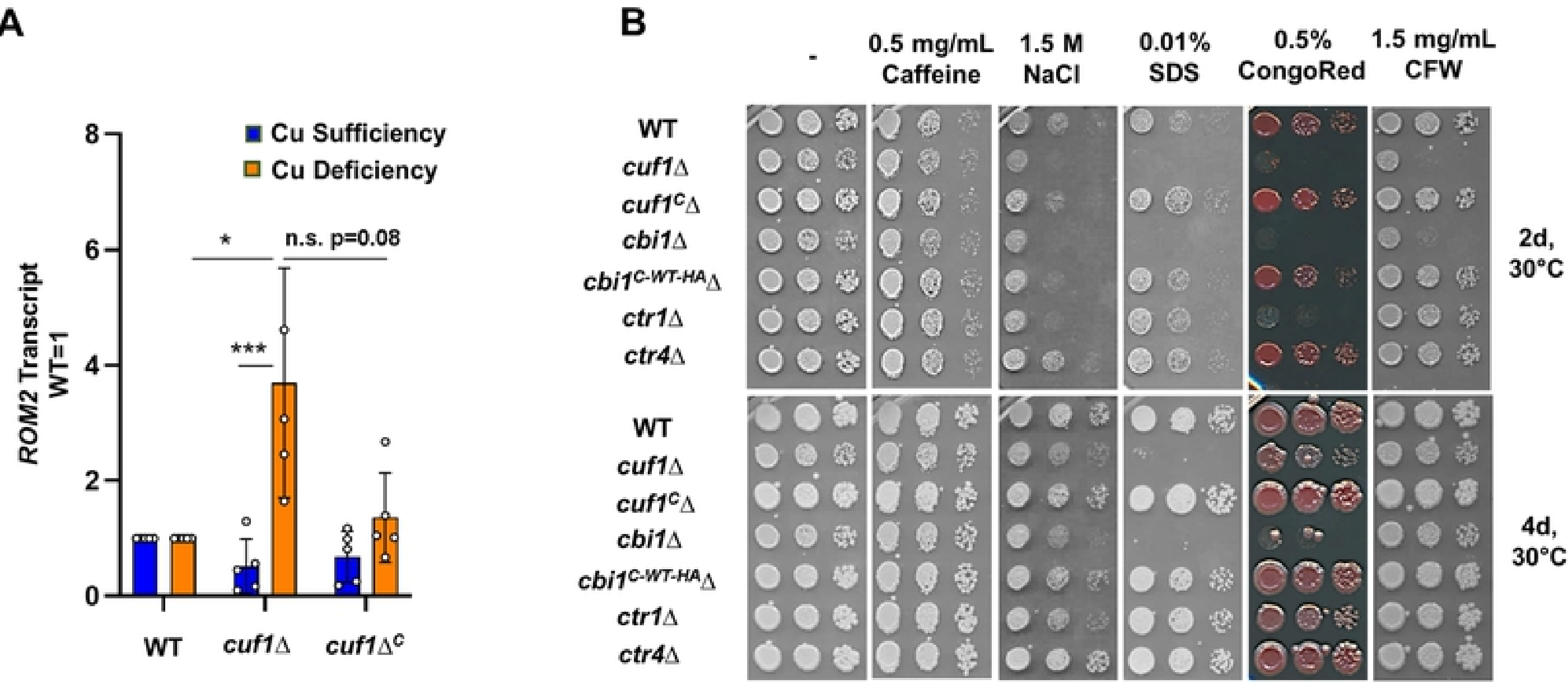

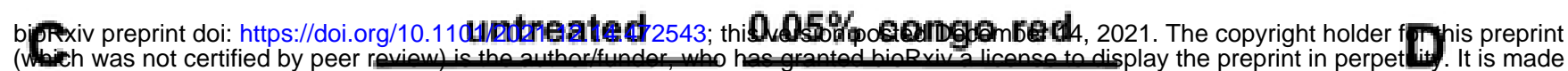
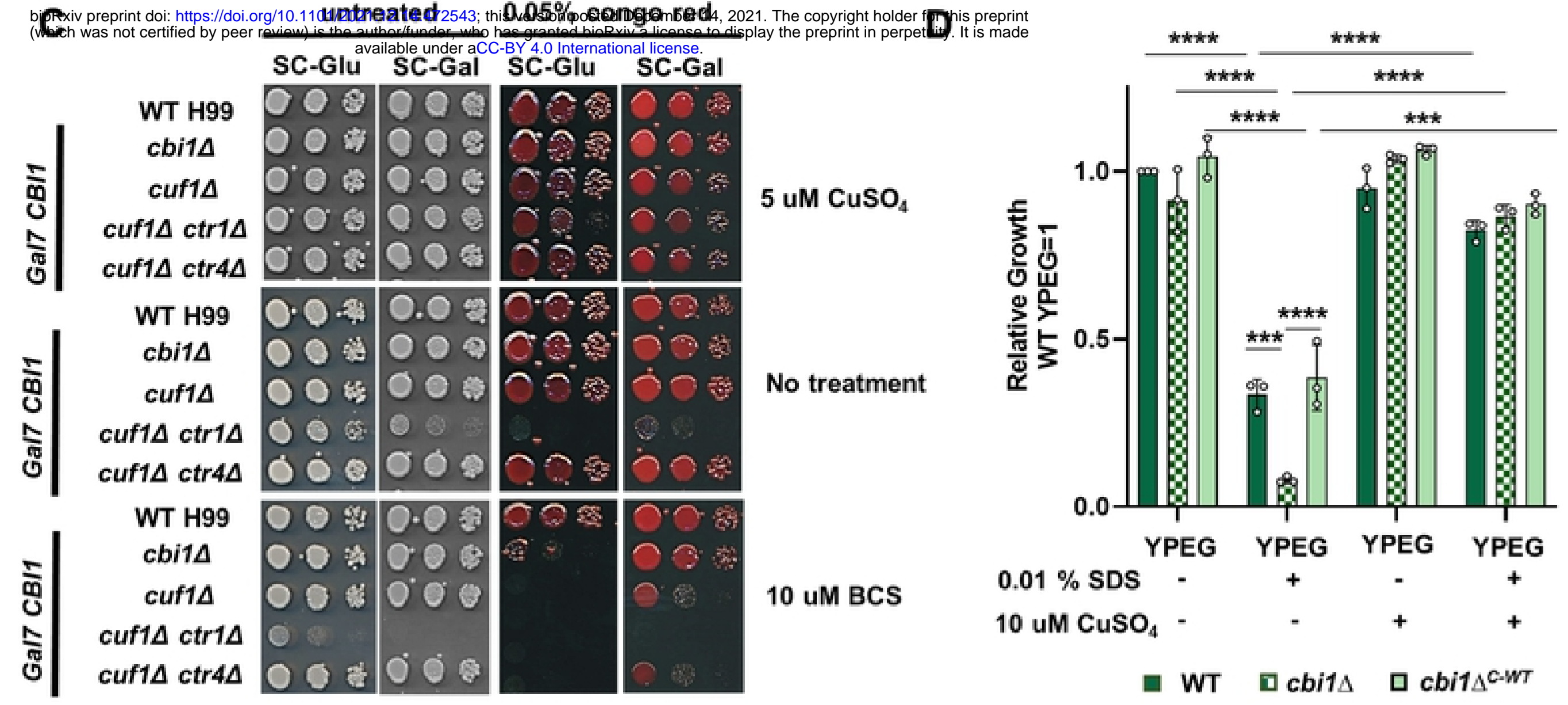

E

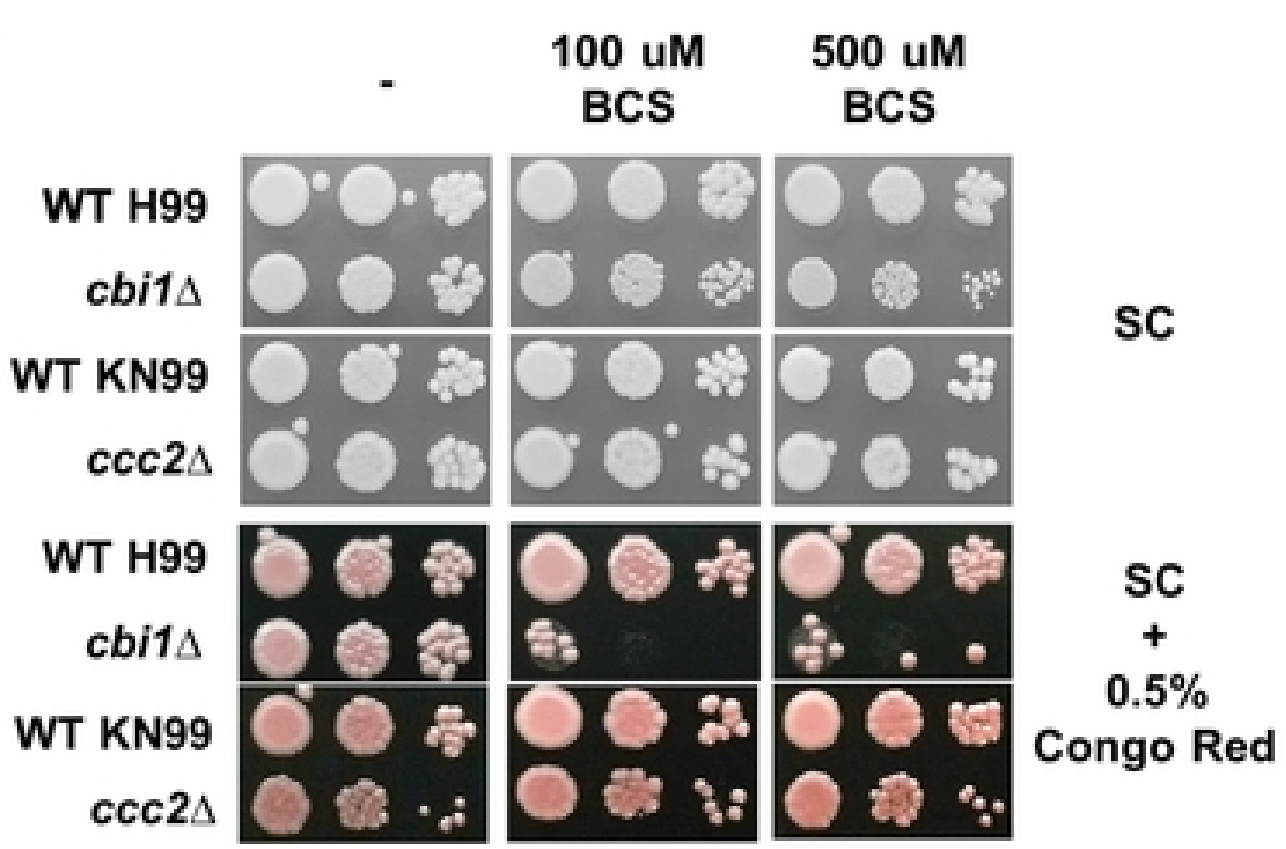

F

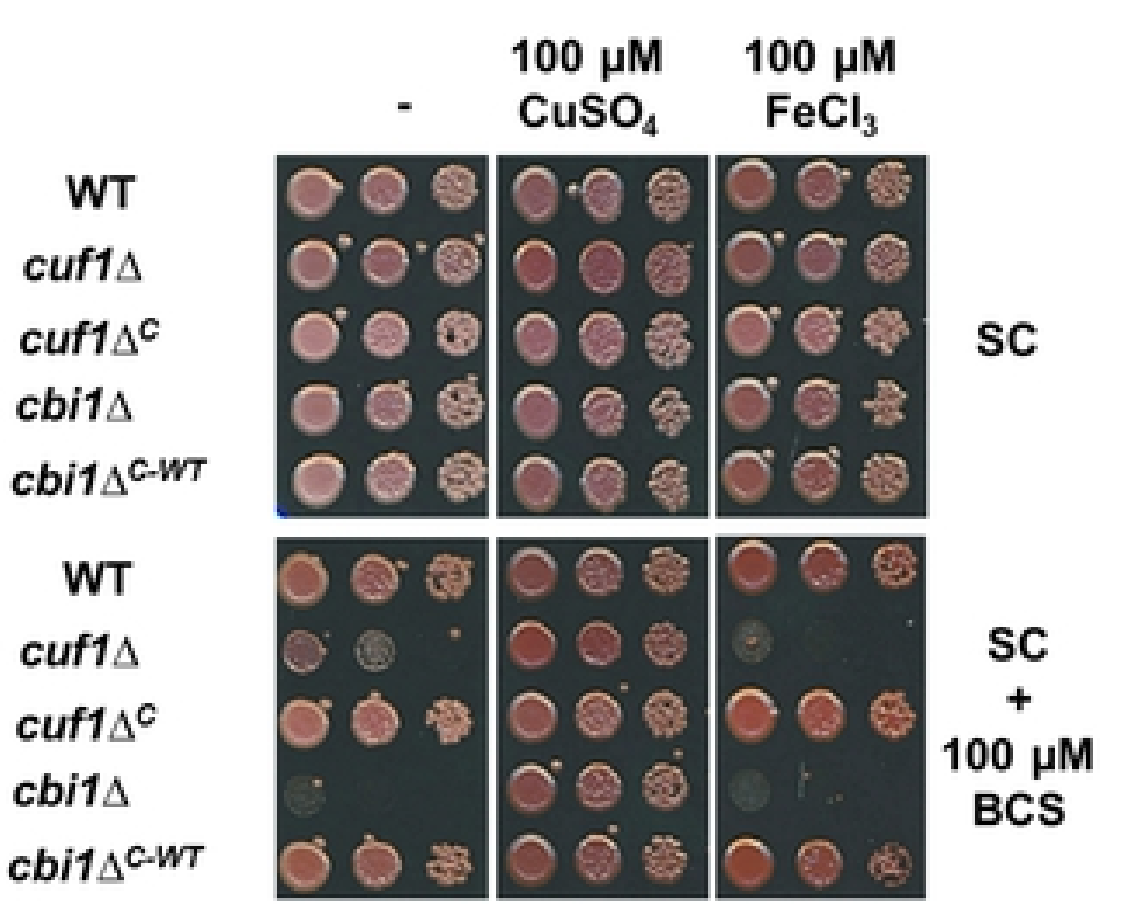




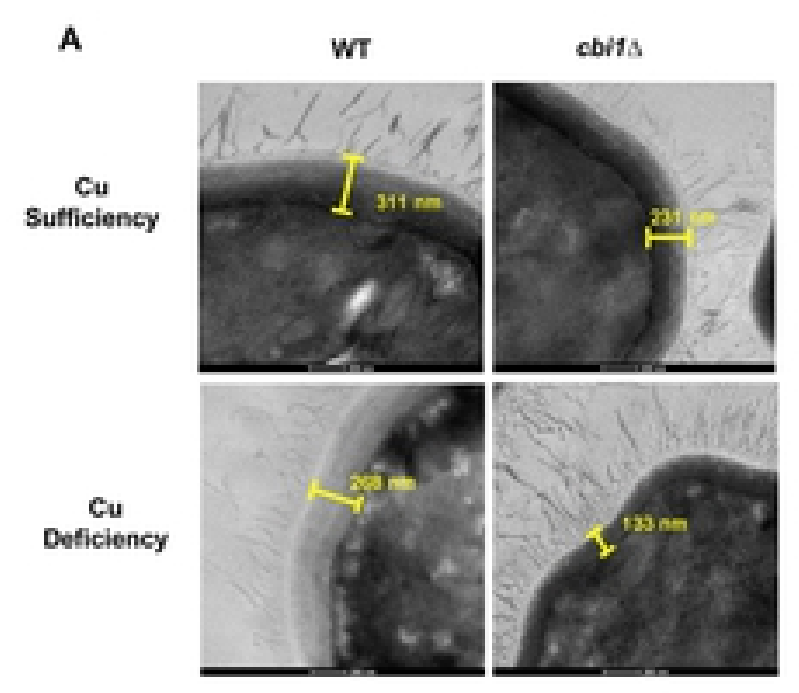

D

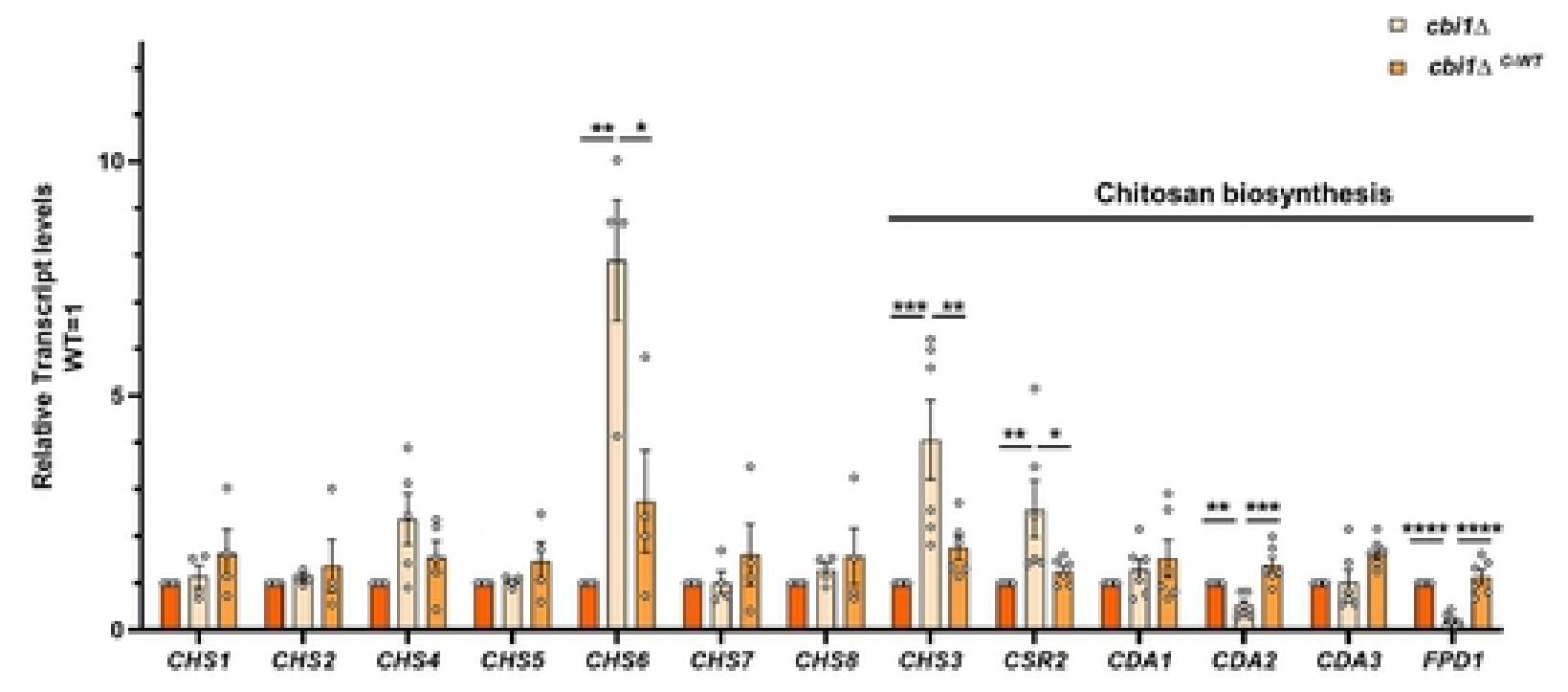

C

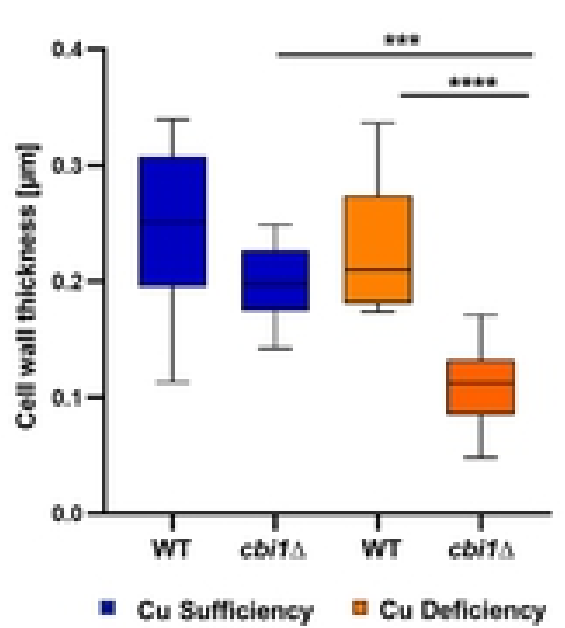

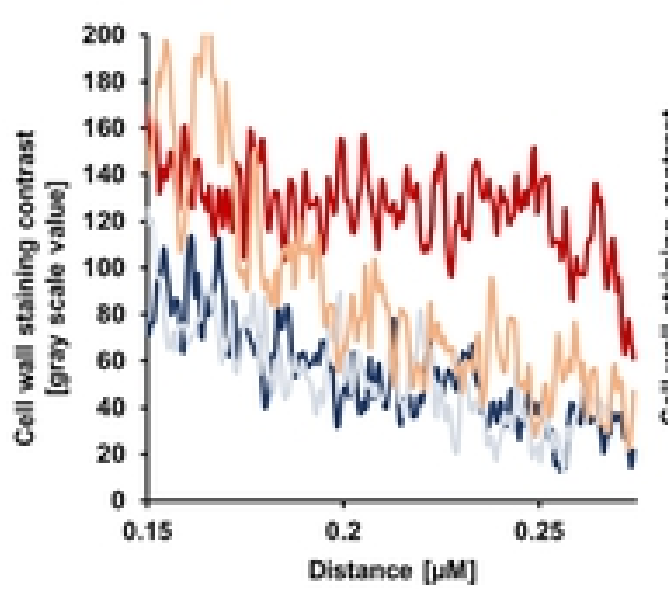

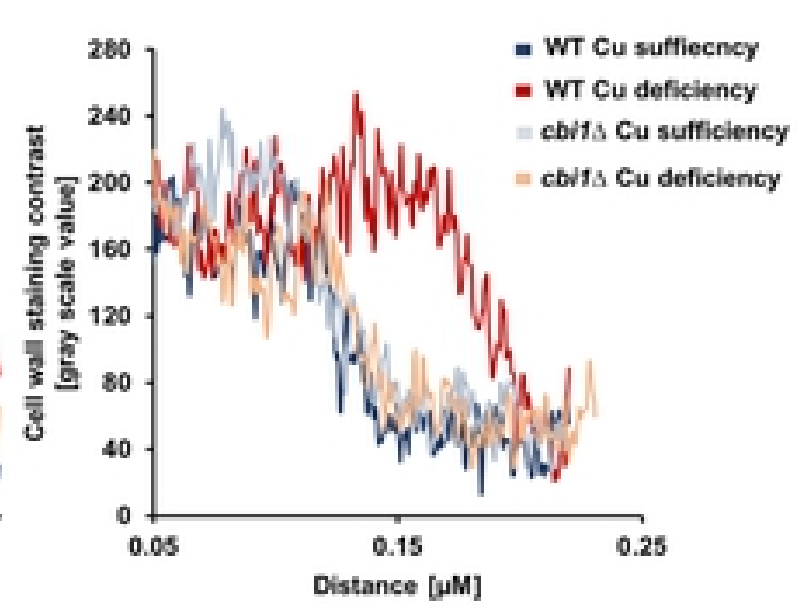

E

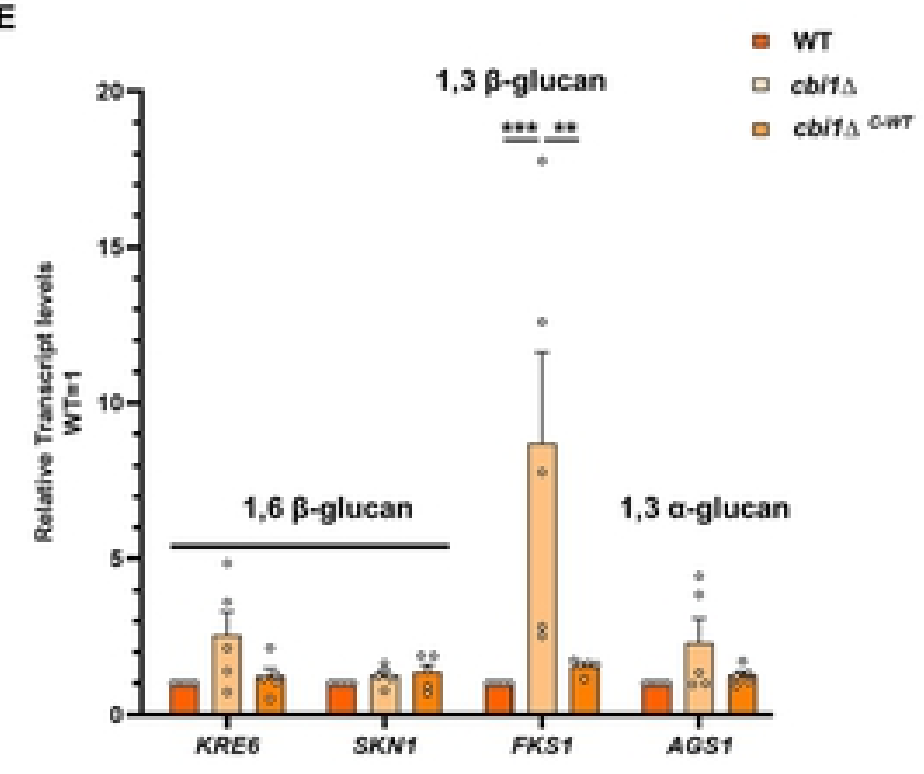

Figure 2

Figure 2 
A

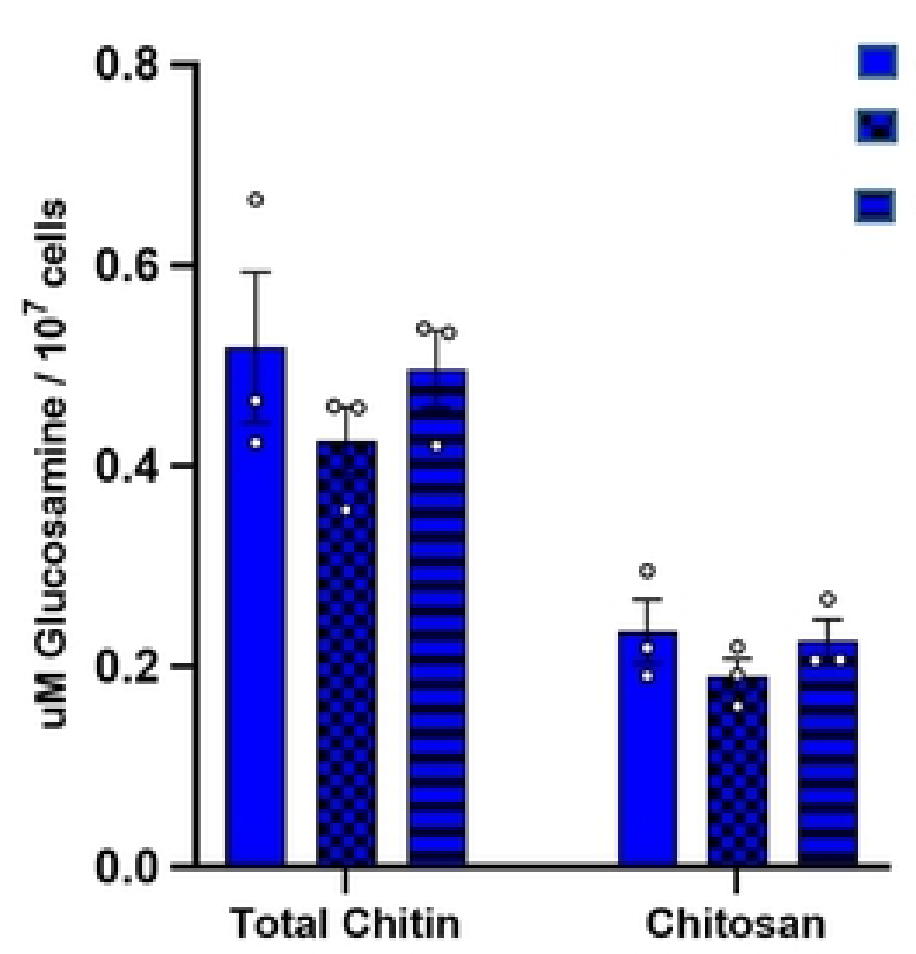

C

CFW

WGA-Alexa 488

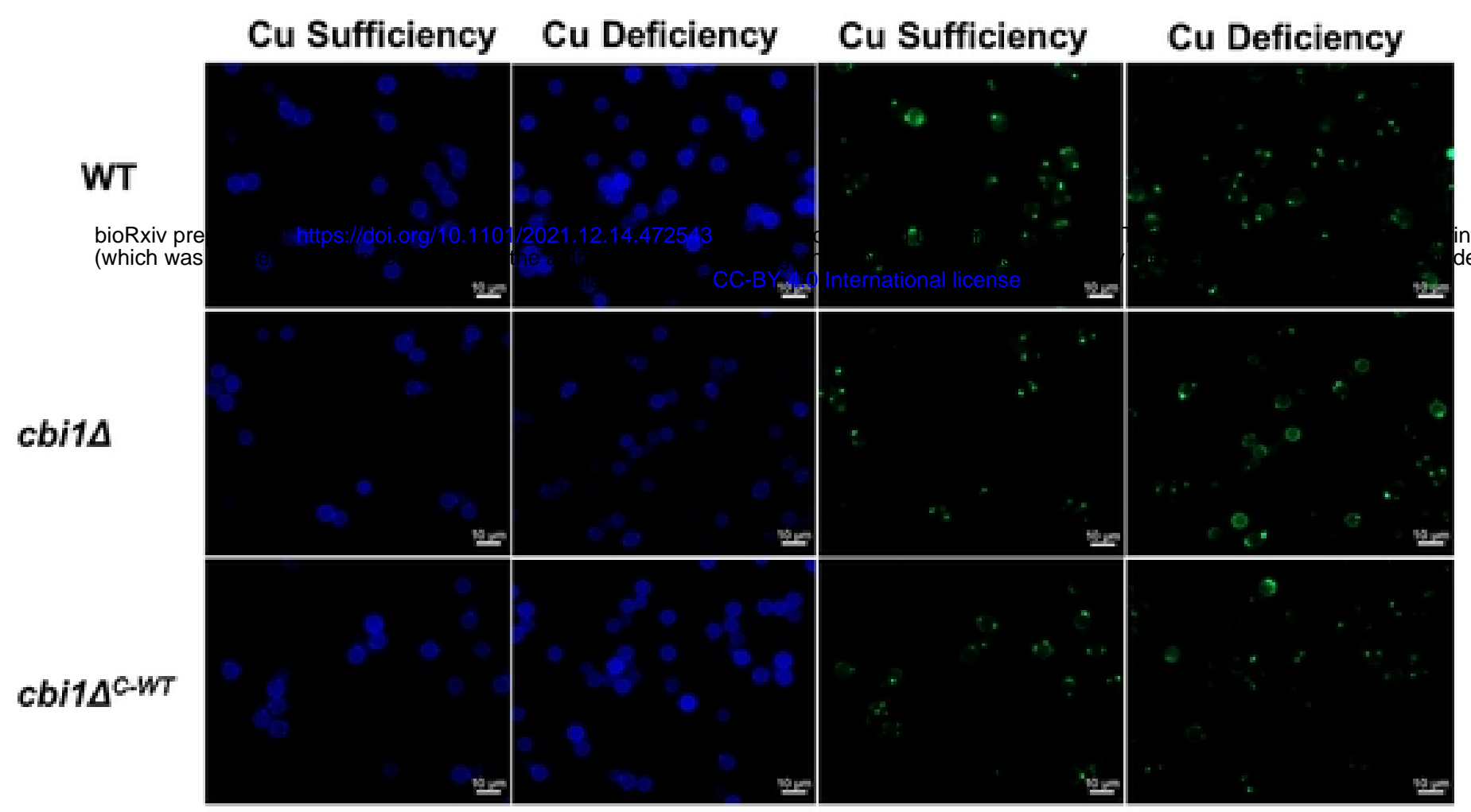

WT

cbi14

$c^{c b i 1 \Delta^{c-w r}}$

Cu Sufficiency Cu Deficiency

E

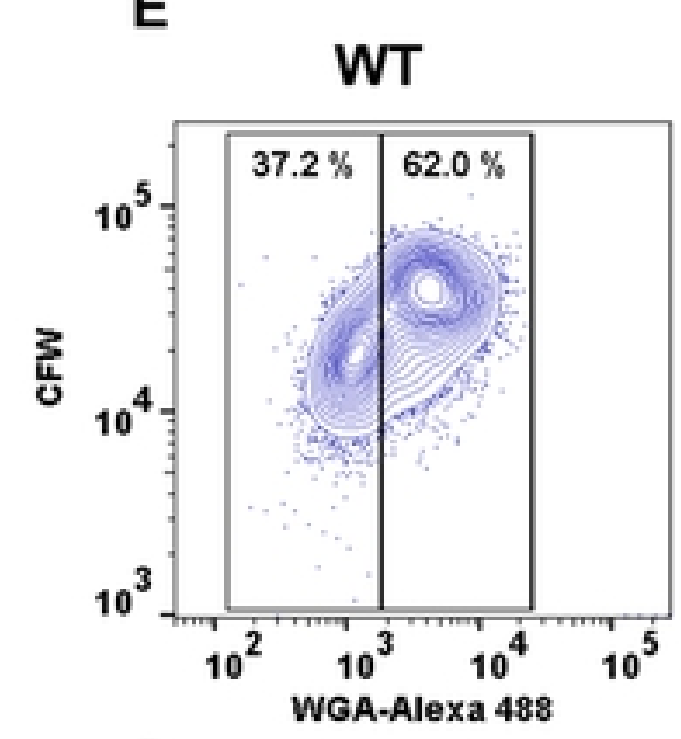

G

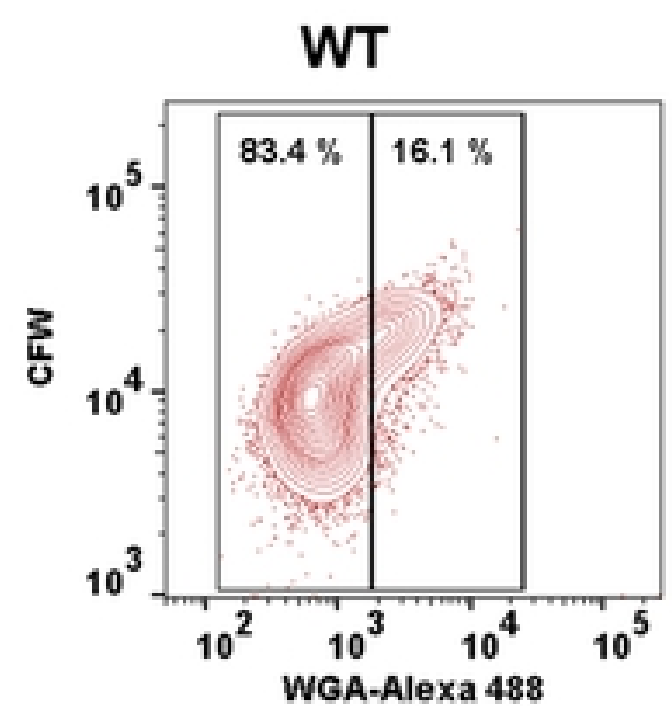

WT

cbi1 $^{c-W T}$
B

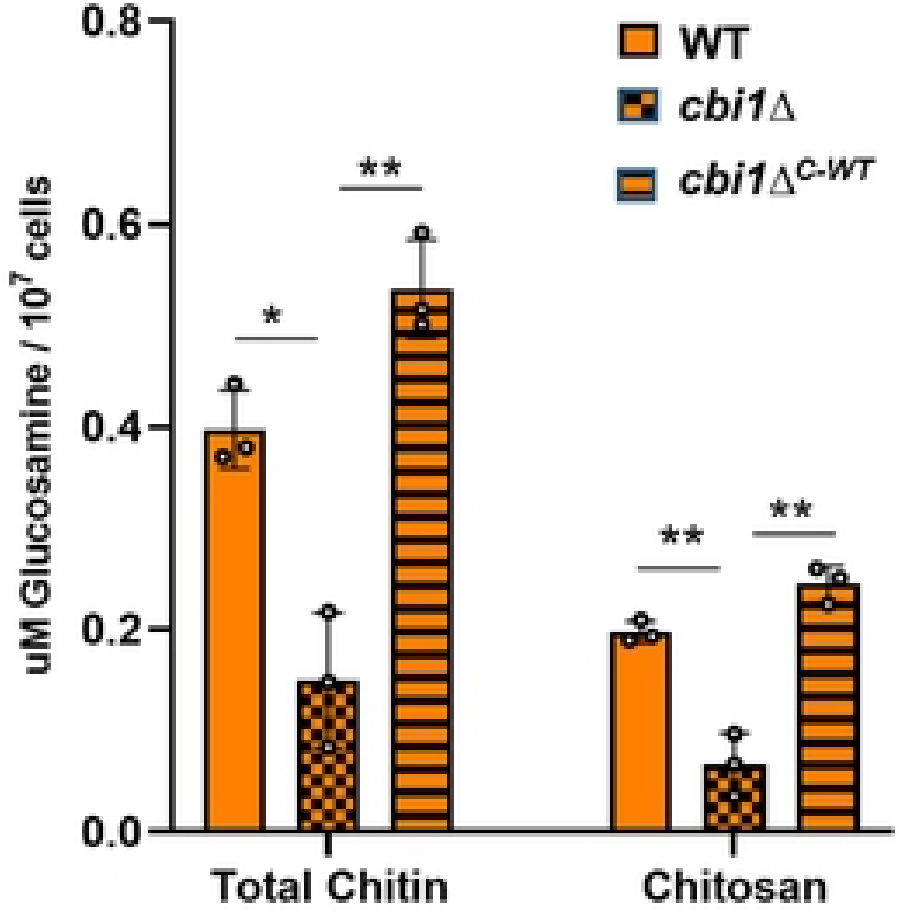

D

EosinY

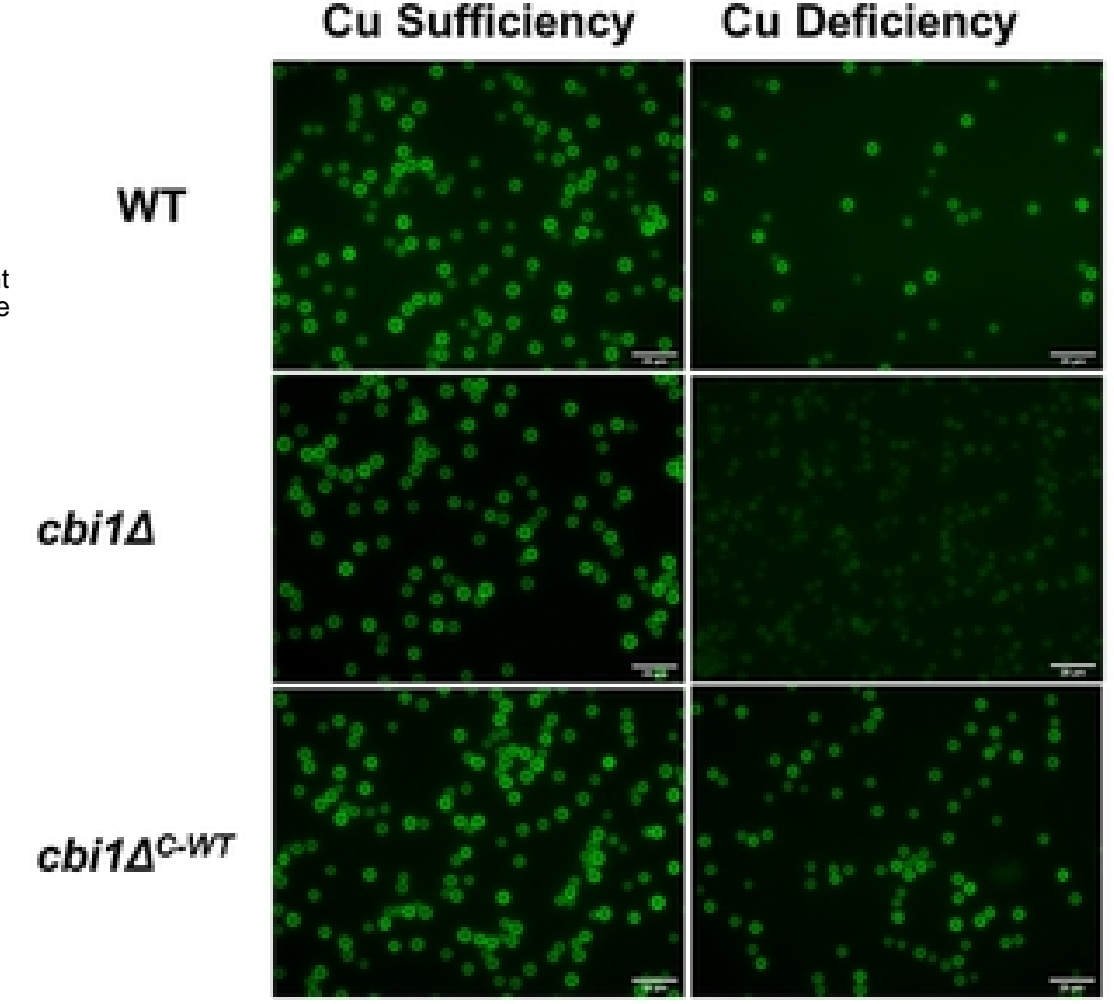

F
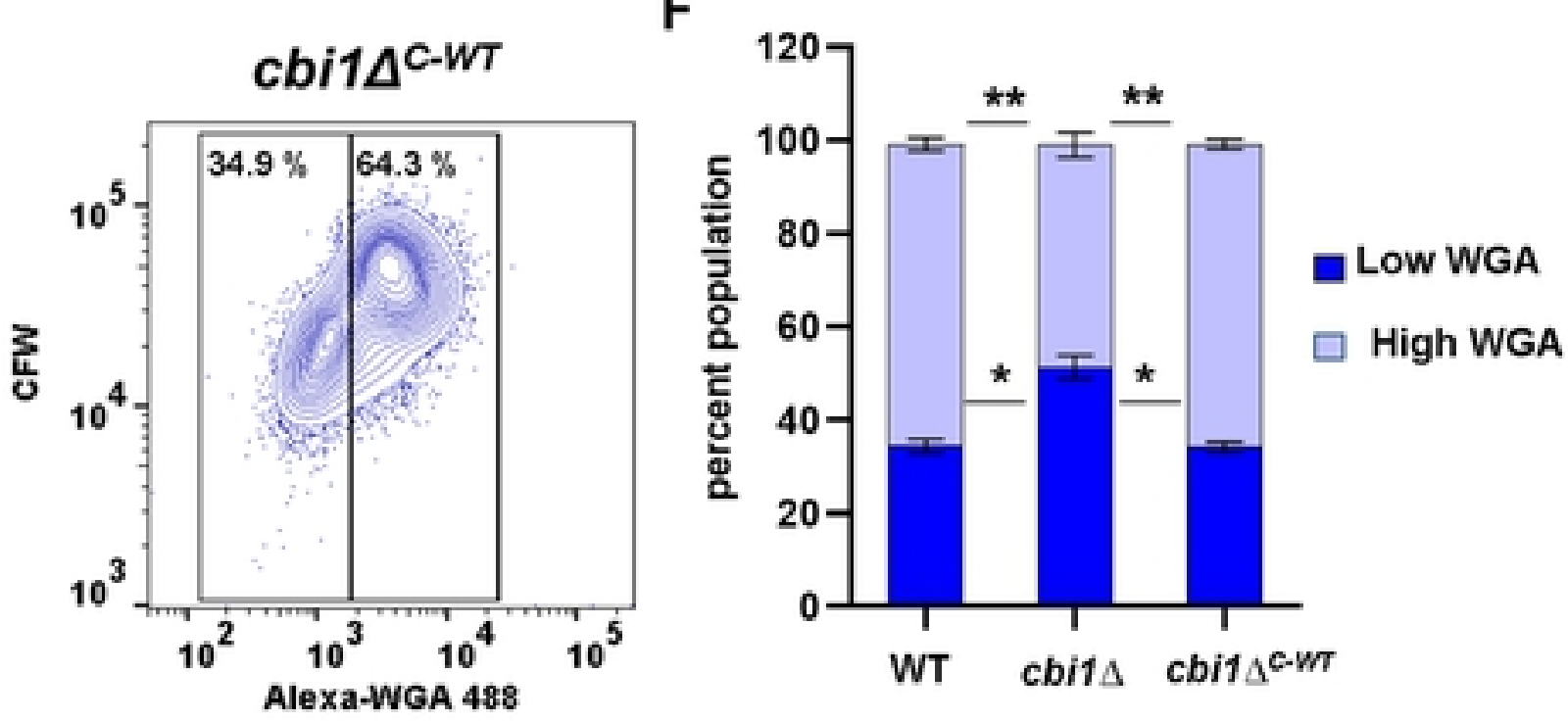

H
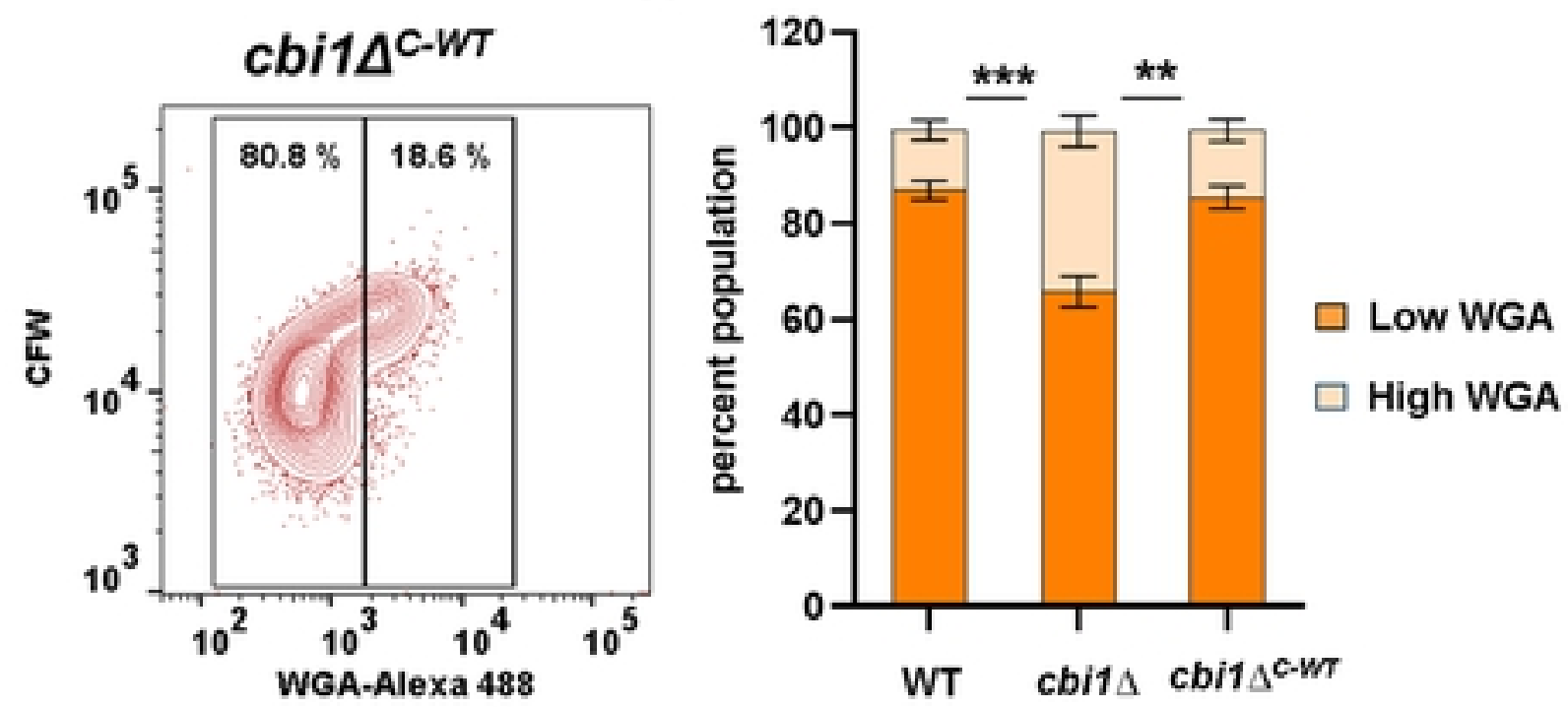

Figure 3

Figure 3 


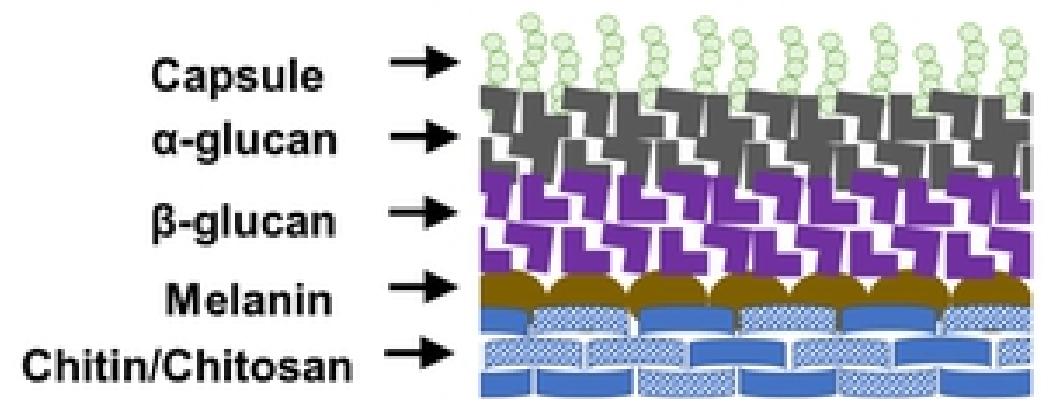

B

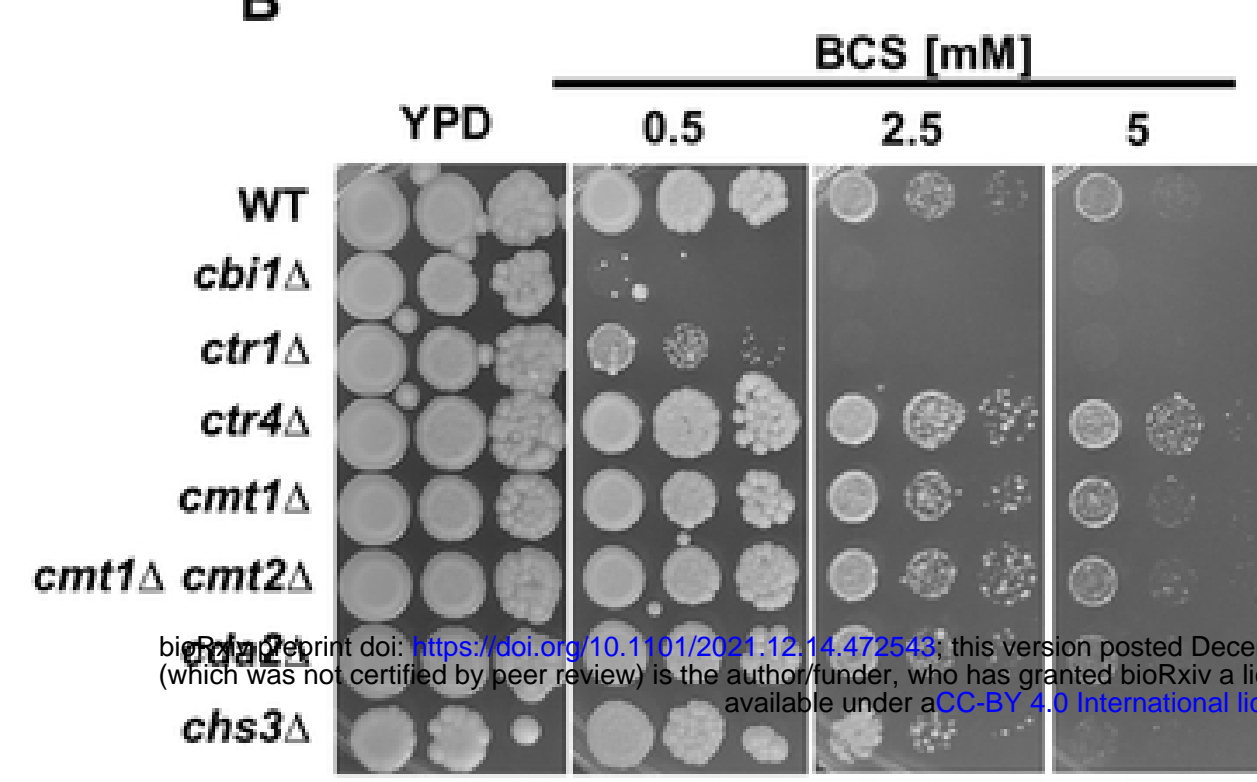

Strains impacting chitin : chitosan ratio

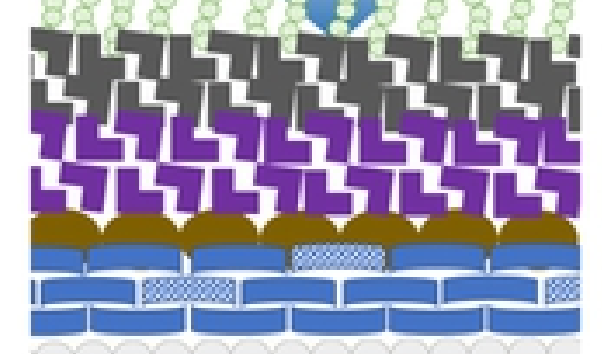

C

$\mathrm{CuSO}_{4}[\mathrm{mM}]$

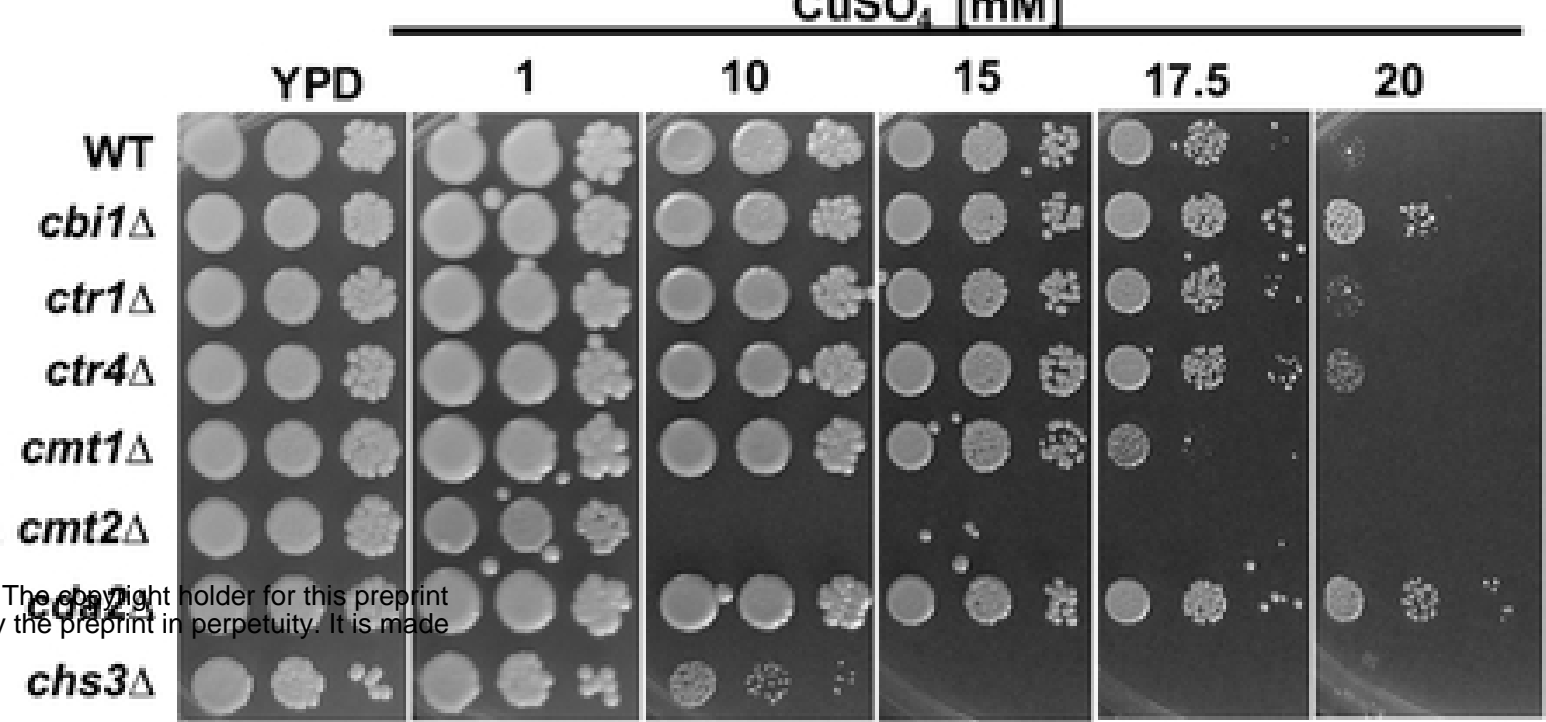


A

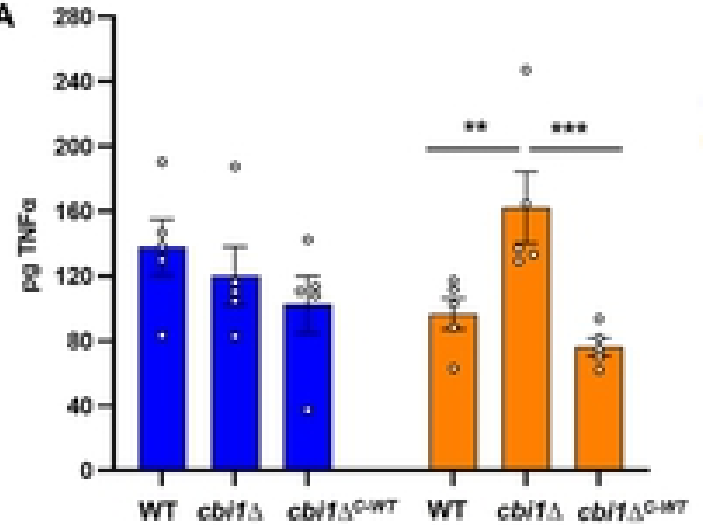

B

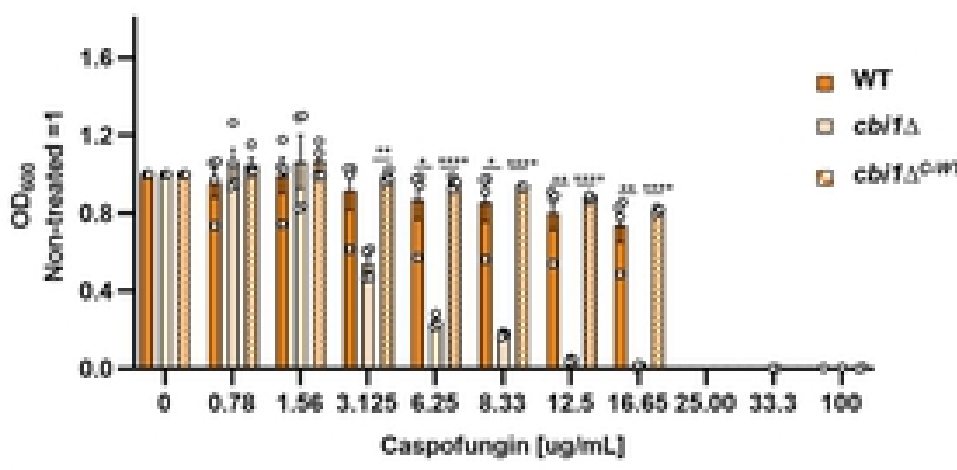

c

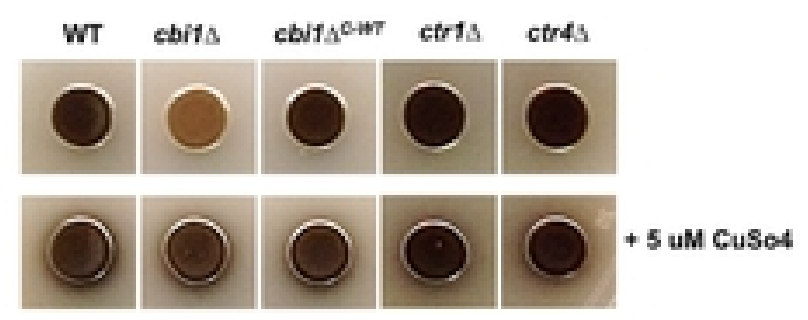

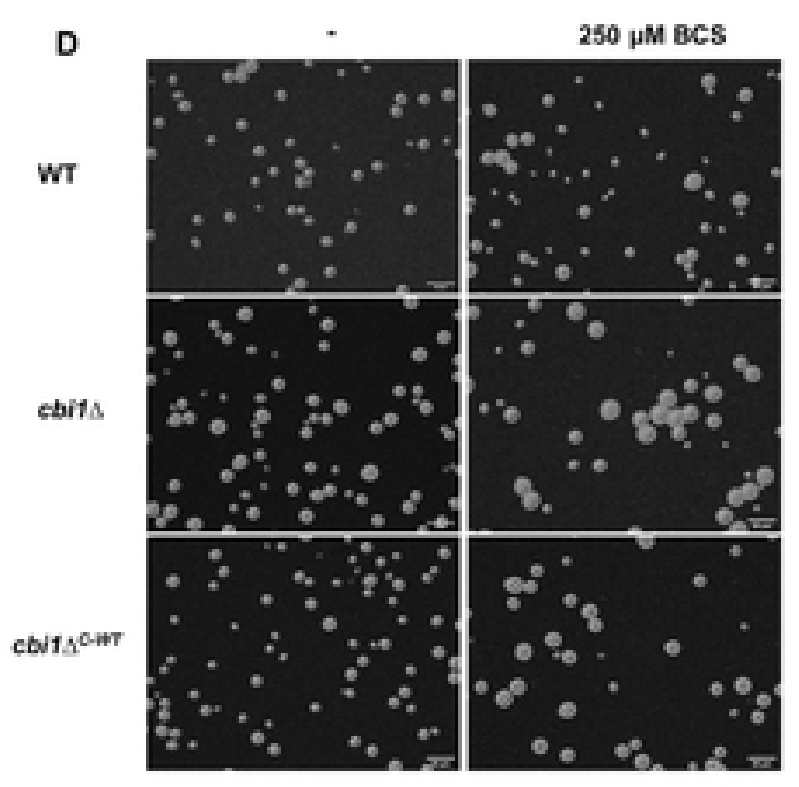

E

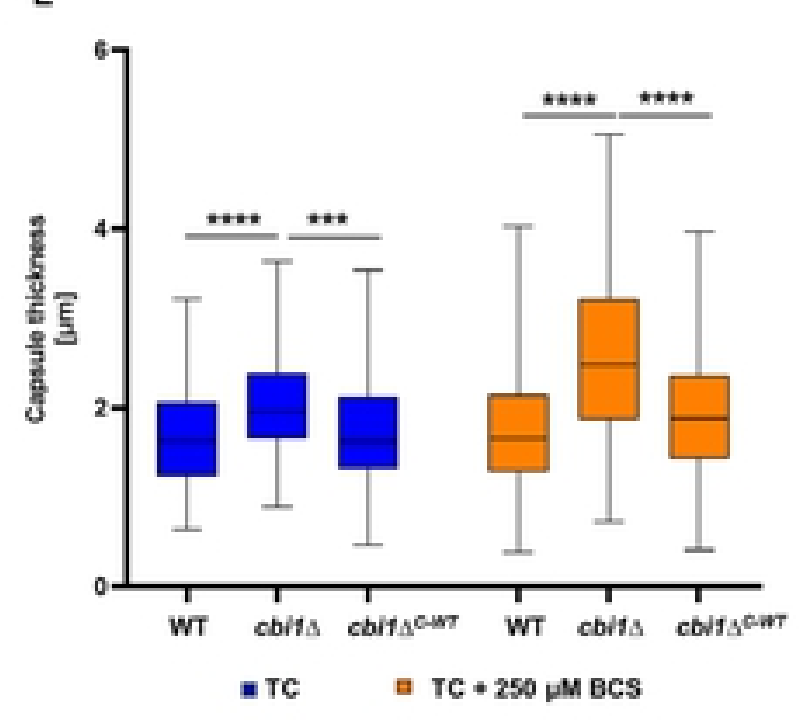

F

wT

cbins

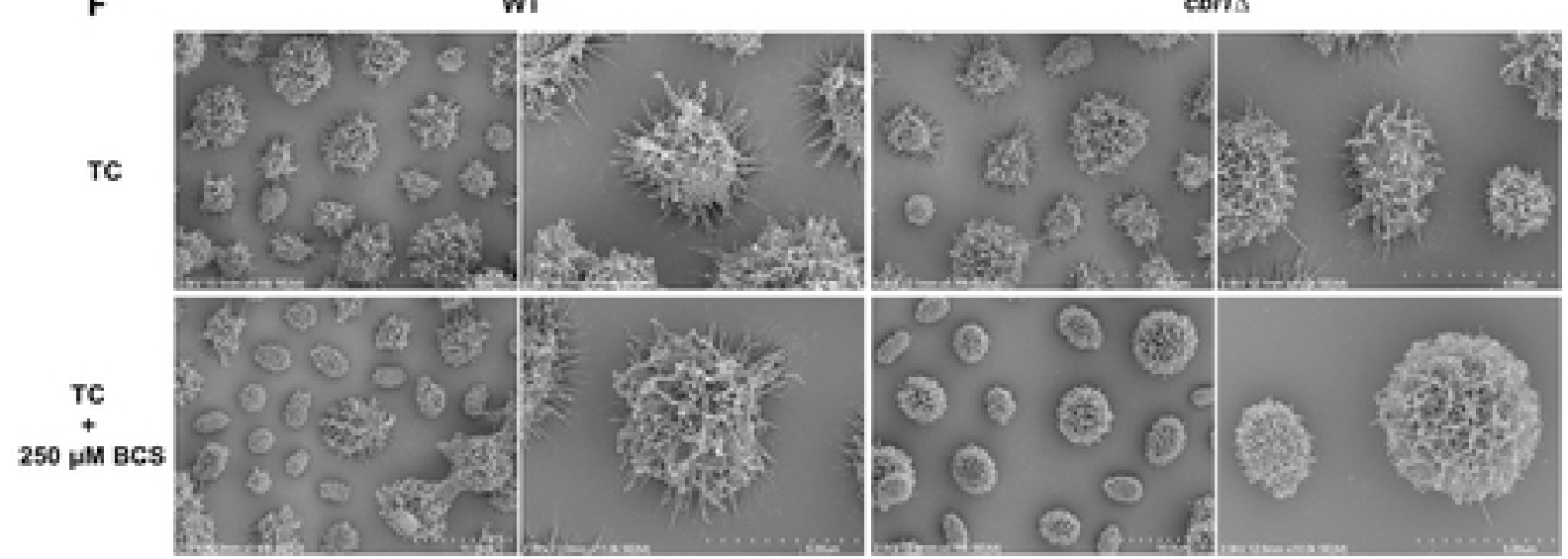

Figure 5

Figure 5 